\title{
Effects of recombinant bovine interleukin-8 (rblL-8) treatment on health, metabolism, and lactation performance in Holstein cattle IV: Insulin resistance, dry matter intake, and blood parameters
}

\author{
M. Zinicola, ${ }^{1}$ C. P Batista, ${ }^{1}$ L. Bringhenti, ${ }^{1}$ E. B. S. Meira Jr., ${ }^{1}$ F. S Lima, ${ }^{2}$ S. P. McDonough, ${ }^{1}$ and R. C. Bicalho ${ }^{1 *}$ \\ ${ }^{1}$ Department of Population Medicine and Diagnostic Sciences, Cornell University, Ithaca, NY 14853-6401 \\ ${ }^{2}$ Department of Veterinary Clinical Medicine, University of Illinois, Urbana-Champaign 61802
}

\section{ABSTRACT}

We have shown in 2 independent studies that cows who received recombinant bovine interleukin-8 (rbIL8) administered intrauterinely shortly after parturition have a significant and long-lasting increase in milk yield. In the present study, we hypothesized that the increased milk production associated with rbIL- 8 treatment is a consequence of increased postpartum dry matter intake (DMI) and orchestrated homeorhetic changes that prioritize milk production. Cows were enrolled into 1 of 3 treatment groups: those assigned to the control group $(\mathrm{CTR} ; \mathrm{n}=70)$ received an intrauterine (IU) administration of $500 \mathrm{~mL}$ of Dulbecco's phosphate-buffered saline (DPBS) solution and $1 \mathrm{~mL}$ of DPBS solution intravenously (IV; jugular vein), those assigned to the rbIL-8 IV group (rbIL8-IV, $\mathrm{n}=70$ ) received an IV injection of $167 \mu \mathrm{g}$ of rbIL-8 and $500 \mathrm{~mL}$ of DPBS solution IU, and cows assigned to the rbIL-8 IU group (rbIL8-IU, $\mathrm{n}=70$ ) received an IU administration with $1,195 \mu \mathrm{g}$ of rbIL-8 diluted in $499.5 \mathrm{~mL}$ of DPBS solution and $1 \mathrm{~mL}$ of DPBS solution IV. Animals were housed in a tiestall from calving to $30 \mathrm{~d}$ in milk (DIM) to measure DMI. Blood samples were collected daily from calving to 7 DIM and weekly until 28 DIM. Insulin resistance was evaluated using an intravenous glucose tolerance test and intravenous insulin challenge test (IVICT) in a subgroup of cows $(n=20 /$ treatment $)$ at 10 and 11 DIM, respectively. Additionally, liver biopsy samples were taken at 14 DIM from the same subgroup of cows to measure triglyceride levels and cell proliferation and apoptosis. Cows treated with rbIL8-IU produced more milk $(\mathrm{CTR}=36.9 \pm 1.5$; rbIL8-IU $=38.5 \pm 1.5$; rbIL8$\mathrm{IV}=36.6 \pm 1.5 \mathrm{~kg} / \mathrm{d})$, energy-corrected milk (CTR $=42.9 \pm 0.9 ;$ rbIL8-IU $=46.1 \pm 0.8 ;$ rbIL8-IV $=43.7$ $\pm 0.9 \mathrm{~kg} / \mathrm{d})$, and fat-corrected milk $(\mathrm{CTR}=44.3 \pm$ $0.9 ;$ rbIL8-IU $=47.8 \pm 0.9 ;$ rbIL8-IV $=45.2 \pm 0.9$

Received January 19, 2019

Accepted May 5, 2019.

*Corresponding author: rcb28@cornell.edu $\mathrm{kg} / \mathrm{d}$ ) yields when compared with CTR cows, and no differences were observed between rbIL8-IV and CTR cows. The administration of rbIL8-IU significantly increased DMI compared with CTR $(\mathrm{CTR}=18.8 \pm 0.3$; rbIL8-IU $=19.9 \pm 0.3 ;$ rbIL8-IV $=19.3 \pm 0.3 \mathrm{~kg} / \mathrm{d})$. Recombinant bIL-8 treatment did not affect glucose, insulin, or fatty acids (i.e., IVICT only) concentrations or their area under the curve in response to an intravenous glucose tolerance test and IVICT when compared with CTR. Moreover, rbIL-8 treatment administered IU or IV increased liver triglyceride levels. Additionally, cows treated with rbIL8-IU tended to have lower odds of developing hyperketonemia (odds ratio $=0.46$, 95\% confidence interval: 0.19 to 1.10), lower odds of clinical ketosis and displaced abomasum combined (odds ratio $=0.17,95 \%$ confidence interval: 0.03 to 0.89 ), and lower odds of diseases combined (odds ratio $=0.43,95 \%$ confidence interval: 0.21 to 0.86 ) when compared with CTR. We conclude that the administration of rbIL8-IU increases DMI, milk production, fat-corrected milk, and energy-corrected milk while improving overall health during the postpartum period. This study supports the use of rbIL-8 administered IU shortly after calving to improve health and production responses in lactating cows.

Key words: interleukin-8, dry matter intake, metabolism, milk production

\section{INTRODUCTION}

Dairy cows face numerous metabolic adaptations in the transition from late gestation to early lactation. During this transition, homeorhetic mechanisms allow dairy cows to produce copious amount of milk without compromising their own health and welfare (Bauman and Currie, 1980; Baumgard et al., 2017). However, the failure to adapt can lead to low milk production, health disorders, and poor reproductive performance (Dubuc et al., 2011; Chapinal et al., 2012; Bicalho et al., 2017). Thus, a successful lactation is dependent on the cow's ability to orchestrate adaptions that coordinate body 
tissue metabolism and nutrient trafficking to maximize milk synthesis and health.

Several hormones, such as insulin and growth hormone $(\mathbf{G H})$, are considered as key regulators of nutrient partitioning (Bell, 1995; Lucy et al., 2009). At the onset of lactation, blood insulin levels rapidly decrease, then slowly increase during the progression of lactation (Zinicola and Bicalho, 2019). Conversely, blood GH concentrations significantly increase, then decrease as lactation progresses (Lucy et al., 2009). As a result, a series of adaptations such as increased lipolysis, increased gluconeogenesis, and decreased uptake of glucose by peripheral tissues ensure adequate nutrient supply to support lactation (Bell, 1995). Furthermore, transient insulin resistance allows for glucose to be spared by peripheral tissues and directed toward synthesis of lactose in the mammary gland (Bell and Bauman, 1997; De Koster and Opsomer, 2013).

We have demonstrated that a single intrauterine administration of bovine recombinant interleukin- 8 (rbIL-8) within $12 \mathrm{~h}$ of parturition significantly increased milk production, ECM, and FCM yields during the first 6 mo of lactation (Zinicola et al., 2019a). Interestingly, we also observed that the increased milk production following intrauterine rbIL-8 treatment was not associated with a higher incidence of hyperketonemia (HYK) and clinical ketosis $(\mathbf{C K})$. In fact, the incidence of HYK and CK was lower in cows treated with rbIL-8 compared with controls, both only numerically. These results suggested that the production responses following rbIL-8 administration might be associated with an improved metabolic health (Zinicola et al., 2019a).

Interleukin-8 has been associated with insulin resistance (Fujishiro et al., 2003; Kobashi et al., 2009; Hardy et al., 2011). In fact, we have demonstrated that systemic administration of rbIL-8 in Holstein calves induces insulin resistance (Zinicola et al., 2019b). Moreover, IL- 8 belongs to a subset of chemokines associated with angiogenic properties (Onuffer and Horuk, 2002), and mitogenic and antiapoptotic effects (Colletti et al., 1998; Hogaboam et al., 1999; Osawa et al., 2002).

Furthermore, we suggested that rbIL-8 treatment might exacerbate the un-coupling of the $\mathrm{GH} / \mathrm{IGF}-1$ axis that postpartum cows experience during early lactation. Cytokines are known to alter the GH signaling via suppressors of cytokine signaling protein production, which will result in lower production of IGF-1 and thus exacerbate the un-coupling of the GH/IGF-1 axis (Bazan, 1989; Stevenson et al., 2004; Rico-Bautista et al., 2006). As a result, dairy cows might benefit from the well-known effects of GH on homeorhesis, which will lead to more milk production (Bauman and Vernon, 1993; Bell and Bauman, 1997; Baumgard et al., 2017).
In contrast with our hypothesis, we have demonstrated that systemic administration of rbIL-8 in male Holstein calves does not alter GH and IGF-1 plasma concentrations (Zinicola et al., 2019b). However, the possible effect of rbIL-8 treatment on blood GH and IGF-1 levels in lactating animals is unknown.

We have proposed that the potential underlying mechanisms responsible for the increased milk production observed in Holstein cows following rbIL-8 treatment might involve one or more of the following biological processes: (1) insulin resistance; (2) dysregulation of the GH/IGF-1 axis; (3) increased hepatocyte proliferation and decreased apoptosis; and (4) increased DMI. The primary objectives of the current study were to evaluate whether rbIL- 8 treatment within $12 \mathrm{~h}$ of parturition would increase milk production through effects on insulin resistance, DMI, liver cell proliferation, and apoptosis, or by promoting the un-coupling of the GH/IGF-1 axis (or both).

\section{MATERIALS AND METHODS}

\section{Ethics Statement}

The research protocol was reviewed and approved by the Cornell University Institutional Animal Care and Use Committee (protocol number 2016-0065). The methods were carried out in accordance with the approved guidelines.

\section{Animals, Housing, and Experimental Design}

The study was conducted at the Cornell Dairy Teaching and Research Center, located in Harford, New York. The experimental farm has the capacity to house 80 cows in a tiestall barn equipped with sawdust bedding, exhausters, ad libitum access to water, and completely separated feed bunks that allows accurate evaluation of feed intake. Additionally, 500 lactating cows are housed in a freestall barn, sand bedding, fans, and ad libitum access to feed and water. Animals were housed at the tiestall facilities from calving to 30 DIM. At 31 DIM, cows were moved to the freestall facilities until the end of the study period (180 DIM). From 0 to 30 DIM, cows were fed once daily (between 0630 and 0730 h) at $110 \%$ of expected consumption and individual feed intake was measured by weighing the amount of feed offered and refused daily. Total mixed ration was sampled weekly and evaluated for DM content $\left(55^{\circ} \mathrm{C}\right.$ for $48 \mathrm{~h}$ ). Weekly dried TMR samples were ground to pass the 2-mm screen of a Wiley mill (Arthur H. Thomas, Philadelphia, PA), and monthly composites of dried TMR samples were sent to a commercial laboratory (Dairy One Cooperative Inc., Ithaca, NY) for 
chemical composition analysis; ingredients and chemical composition of the ration are presented in Tables 1 and 2, respectively. Individual feed intakes were recorded daily and corrected for weekly DM contents; weekly averages of DMI were used for data analysis. From 31 to 180 DIM, cows were fed twice daily in a freestall barn equipped with headlock stations. Cows were milked thrice daily; milk weights were recorded at each milking. Nulliparous animals were moved to the tiestall barn $21 \pm 3 \mathrm{~d}$ from the anticipated calving date and were exercised 3 times per wk until calving to acclimate them to tiestalls. Multiparous cows were moved to the tiestall barn within $12 \mathrm{~h}$ of parturition.

Cows received first service timed AI (TAI) at 64 to 70 DIM after synchronization of ovulation with the

Table 1. Ingredients (DM basis) of postpartum diet

\begin{tabular}{|c|c|}
\hline Ingredient & $\%$ of $\mathrm{DM}$ \\
\hline Alfalfa hay & 3.60 \\
\hline Wheat straw & 0.90 \\
\hline Canola meal & 4.50 \\
\hline Ear corn, high-moisture & 10.80 \\
\hline Mixed-legume grass silage & 10.80 \\
\hline Corn silage & 43.55 \\
\hline Energy Booster $100^{1}$ & 1.35 \\
\hline Celmanex ${ }^{2}$ & 0.22 \\
\hline Amino Plus ${ }^{3}$ & 7.37 \\
\hline Dried molasses & 3.74 \\
\hline Citrus pulp & 3.51 \\
\hline Soybean hulls & 2.25 \\
\hline Blood meal & 1.68 \\
\hline Fermenten $^{4}$ & 0.77 \\
\hline Urea & 0.45 \\
\hline Megalac $R^{5}$ & 0.36 \\
\hline Ethyl-cellulose $\mathrm{RPM}^{6}$ & 0.04 \\
\hline Na bicarbonate & 1.49 \\
\hline $\mathrm{MIN} \mathrm{AD}^{7}$ & 0.53 \\
\hline Dynamate $^{8}$ & 0.53 \\
\hline Salt & 0.53 \\
\hline Mineral $\operatorname{mix}^{9}$ & 0.22 \\
\hline Monocalcium phosphate & 0.21 \\
\hline Ca carbonate & 0.21 \\
\hline Mg oxide & 0.27 \\
\hline Rumensin ${ }^{10}$ & 0.06 \\
\hline Vitamin E premix ${ }^{11}$ & 0.05 \\
\hline
\end{tabular}

${ }^{1}$ Commercial fat source, Milk Specialties Global, Eden Prairie, MN.

${ }^{2}$ Yeast product, Church \& Dwight Co. Inc., Ewing Township, NJ.

${ }^{3}$ Heat-treated soybean meal. Ag Processing Inc., Omaha, NE.

${ }^{4}$ Rumen fermentation enhancer, Church \& Dwight Co. Inc.

${ }^{5}$ Rumen bypass fat, Church \& Dwight Co. Inc..

${ }^{6}$ Ethyl-cellulose rumen-protected methionine, Evonik Nutrition and Care GmbH, Hanau-Wolfgang, Germany.

${ }^{7} \mathrm{Ca}-\mathrm{Mg}$ dolomite, Papillon Agricultural Company, Easton, MD.

${ }^{8} \mathrm{~K} \mathrm{Mg}$ sulfate, The Mosaic Co., Plymouth, MN.

${ }^{9}$ Contains $25 \% \mathrm{Ca}, 6.5 \% \mathrm{Mg}, 6.3 \% \mathrm{~S}, 300 \mathrm{mg} / \mathrm{kg} \mathrm{I}, 250 \mathrm{mg} / \mathrm{kg} \mathrm{Co}$, $4,000 \mathrm{mg} / \mathrm{kg} \mathrm{Cu}, 500 \mathrm{mg} / \mathrm{kg} \mathrm{Fe}, 13,300 \mathrm{mg} / \mathrm{kg} \mathrm{Zn}, 5,000 \mathrm{mg} / \mathrm{kg} \mathrm{Mn}$, $125.7 \mathrm{mg} / \mathrm{kg} \mathrm{Se}, 581,818 \mathrm{IU} / \mathrm{kg}$ vitamin A, $163.6 \mathrm{IU} / \mathrm{kg}$ vitamin D, and $2,116 \mathrm{IU} / \mathrm{kg}$ vitamin $\mathrm{E}$.

${ }^{10}$ Premix contained 26,400 g/t monensin, Elanco Animal Health, Greenfield, IN.

${ }^{11}$ Contains 44,000 kIU/kg vitamin E.
Table 2. Chemical composition (DM basis) of postpartum diet

\begin{tabular}{lcc}
\hline $\begin{array}{l}\text { Energy and chemical } \\
\text { compostion }\end{array}$ & Mean & SD \\
\hline $\mathrm{NE}_{\mathrm{L}}, \mathrm{Mcal} / \mathrm{kg}$ & 1.64 & 0.02 \\
$\mathrm{NDF}, \%$ & 30.47 & 1.02 \\
$\mathrm{NFC}, \%$ & 39.81 & 1.37 \\
$\mathrm{ADF}, \%$ & 19.73 & 1.50 \\
Starch, \% & 24.92 & 1.53 \\
Crude fat, \% & 3.42 & 0.31 \\
$\mathrm{CP}, \%$ & 17.27 & 0.69 \\
$\mathrm{Ash}, \%$ & 9.1 & 0.38 \\
$\mathrm{Lignin}, \%$ & 2.97 & 0.40 \\
$\mathrm{Ca}, \%$ & 0.88 & 0.04 \\
$\mathrm{P}, \%$ & 0.39 & 0.01 \\
$\mathrm{~K}, \%$ & 1.69 & 0.16 \\
$\mathrm{Na}, \%$ & 0.72 & 0.02 \\
$\mathrm{Mg}, \%$ & 0.48 & 0.01 \\
$\mathrm{Fe}, \mathrm{mg} / \mathrm{kg}$ & 339 & 45.7 \\
$\mathrm{Zn}, \mathrm{mg} / \mathrm{kg}$ & 66 & 5.38 \\
$\mathrm{Cu}, \mathrm{mg} / \mathrm{kg}$ & 17 & 1.73 \\
$\mathrm{Mn}, \mathrm{mg} / \mathrm{kg}$ & 47 & 2.10 \\
$\mathrm{Mo}, \mathrm{mg} / \mathrm{kg}$ & 1.5 & 0.30 \\
\hline
\end{tabular}

${ }^{1}$ Values represent averages of 8 monthly composited samples. Chemical composition analysis was performed by Dairy One Cooperative Inc., Ithaca, NY.

Double-Ovsynch protocol (GnRH, 7 d later $\mathrm{PGF}_{2 \alpha}, 3 \mathrm{~d}$ later $\mathrm{GnRH}, 7 \mathrm{~d}$ later $\mathrm{GnRH}, 7 \mathrm{~d}$ later $\mathrm{PGF}_{2 \alpha}, 1 \mathrm{~d}$ later $\mathrm{PGF}_{2 \alpha}, 32 \mathrm{~h}$ later $\left.\mathrm{GnRH}\right)$. After first service, cows were inseminated after detection of estrus through a combination of visual observation and automated monitoring of physical activity (HR-Tags, SCR Dairy, Madison, WI). Pregnancy status was determined $32 \pm 3 \mathrm{~d}$ after AI by transrectal ultrasonography using a $7.5-\mathrm{MHz}$ transducer (Ibex, E.I. Medical, Loveland, CO). After determination of pregnancy status, nonpregnant cows were classified based on the ovarian structures present to receive the Short-Resynch or CIDR-Synch protocol as described in (Wijma et al., 2018). Briefly, cows with a corpus luteum $\geq 15 \mathrm{~mm}$ and a follicle $\geq 10 \mathrm{~mm}$ received the Short-Resynch protocol $\left(\mathrm{PGF}_{2 \alpha}, 1 \mathrm{~d}\right.$ later $\mathrm{PGF}_{2 \alpha}, 32 \mathrm{~h}$ later GnRH-16 to $18 \mathrm{~h}$ TAI), whereas cows without a corpus luteum $\geq 15 \mathrm{~mm}$, a follicle $\geq 10 \mathrm{~mm}$, or both received CIDR-Synch (GnRH plus CIDR, $7 \mathrm{~d}$ later $\mathrm{PGF}_{2 \alpha}$ and CIDR removal, $1 \mathrm{~d}$ later $\mathrm{PGF}_{2 \alpha}, 32 \mathrm{~h}$ later GnRH-16 to $18 \mathrm{~h} \mathrm{TAI}$ ). Cows diagnosed pregnant $32 \pm 3 \mathrm{~d}$ after were reexamined $60 \pm 3 \mathrm{~d}$ after AI to reconfirm pregnancy. Cows were considered pregnant for the analysis of time to pregnancy if confirmed pregnant at the second examination.

A total of 210 cows (primiparous, $\mathrm{n}=90$; multiparous, $\mathrm{n}=120$ ) were enrolled between September 2017 and April 2018. Treatment allocation was done by parity (primiparous/multiparous) in 2 separate randomization sheets within $12 \mathrm{~h}$ of parturition. The experimental design was a randomized complete block design with a one-way treatment structure. The blocking factor was 
based on order of calving (order of enrollment). The allotment also indicated the subset of cows (primiparous, $\mathrm{n}=10 /$ treatment; multiparous, $\mathrm{n}=10 /$ treatment) where peripheral response to insulin and glucose disappearance and liver tissue samples were evaluated/ collected. The subset of cows was randomly selected to ensure that they were distributed equally across the duration of the study. The random treatment and blocks were generated using the random number generator function (SAS RANUNI function) of SAS (version 9.4; SAS/STAT, SAS Institute Inc., Cary, NC). If the following conditions were encountered at enrollment, cows were excluded from the study: twins, lameness, milk fever, displaced abomasum (DA), mastitis, and severe injury/trauma.

At the first signs of delivery, cows were moved to individual maternity pens where trained farm personnel assisted with parturition as needed. Cows were enrolled in 1 of 3 treatment groups: those assigned to the control group $(\mathbf{C T R}, \mathrm{n}=70)$ received an intrauterine $(\mathbf{I U})$ administration of $500 \mathrm{~mL}$ of Dulbecco's phosphatebuffered saline (DPBS, \#14190-144; Gibco, Paisley, UK) solution and $1 \mathrm{~mL}$ of DPBS solution intravenously (IV; jugular vein), those assigned to the rbIL-8 IV group (rbIL8-IV, $\mathrm{n}=70$ ) received an IV injection of $167 \mu \mathrm{g}$ of rbIL-8 and $500 \mathrm{~mL}$ of DPBS solution IU, and cows assigned to the rbIL-8 IU group (rbIL8-IU, $\mathrm{n}=70$ ) received an IU administration with $1,195 \mu \mathrm{g}$ of rbIL-8 diluted in $499.5 \mathrm{~mL}$ of DPBS solution and $1 \mathrm{~mL}$ of DPBS solution IV. Recombinant bIL-8 was provided by Zoetis (Zoetis Animal Health, Kalamazoo, MI).

The IU dose used in the current study was selected based on the beneficial effects on puerperal metritis incidence and milk production observed in previous studies; the IU dose used was $1,125 \mu \mathrm{g}$ of rbIL- 8 (Zinicola et al., 2019a). With respect of the IV dose, we speculated that using the same dose used to administer rbIL-8 IU might be too high to be injected systemically. This was the first study that treated lactating cows shortly after calving with rbIL-8 IV. It was unknown how fresh cows would respond to this route of administration. Moreover, considering the size of the uterus and the high volume of lochia present in the uterus within $12 \mathrm{~h}$ of parturition we were not expecting that large amounts of the rbIL-8 administered IU would be absorbed systemically. Therefore, it was decided to treat animals IV with a dose of rbIL- 87 times lower than the dose used to treat animals IU.

\section{Animal Sampling}

Blood samples were collected after feeding (0800 to $1000 \mathrm{~h}$ ) from coccygeal vessels using 10-mL Vacutainer lithium heparin blood collection tubes (Greiner Bio-
One, Monroe, NC) for plasma separation, and 3-mL Vacutainer $\mathrm{K}_{2}$ EDTA tubes (BD Vacutainer, Franklin Lakes, NJ) for complete blood cell counts and genomic testing (Clarifide, Zoetis Animal Health, Kalamazoo, MI). Sampling was done daily from 0 (before treatment) to 7 DIM and weekly from 14 to 28 DIM. After collection, samples were immediately placed on ice. Samples were used for hemogram determination using a Vet hemogram instrument (Heska HemaTrue, Loveland, CO), and plasma was obtained within $1.5 \mathrm{~h}$ of blood collection by centrifugation at $2,000 \times g$ for $15 \mathrm{~min}$ at $4^{\circ} \mathrm{C}$, and frozen at $-80^{\circ} \mathrm{C}$. Plasma concentrations of aspartate aminotransferase, alanine aminotransferase, alkaline phosphatase, gamma glutamyl transferase, BSA, total bilirubin, total protein, creatinine, lactate, cholesterol, urea, glucose, BHB, and fatty acids were determined using an automated clinical chemistry analyzer (Daytona, Randox Laboratories Ltd., Kerneysville, WV), using reagents provided by Randox. Plasma Insulin concentration was determined using a commercial ELISA kit for bovine insulin (Bovine Insulin ELISA, ALPCO, Salem, NH). Following the procedures previously described, a double RIA was used for measuring the plasma concentrations of IGF-1 (Butler et al., 2003, 2004) and GH (Plaut et al., 1987; Rosemberg et al., 1989). A h-IGF-1 receptor grade (lot\# EBB-CO1) from Gropep (Adelaine, Australia) was used for iodination and standards. Primary antibody anti-h-IGF1-rabbit (\#AFP4892898) was obtained from A. F. Parlow at the National Hormone and Pituitary Program and diluted 1:55k for the assay. For the bGH assay, standards and iodinated tracer were made from Upjohn Growth Hormone, Lot \#12, code \#77-001. The NIDDK-antioGH-2 (rabbit) AFPC0123080 was added at 1:35k as the primary antibody. For both assays the second antibody used for precipitation was sheep anti-rabbit gamma globulin supplied by W. R. Butler, Cornell University (Ithaca, NY). Frozen plasma samples were shipped to a Zoetis research and development facility in Kalamazoo (Michigan) for the quantification of endogenous bovine plasma IL-8; the assay used was an in-house-developed Mesoscale Discovery electrochemiluminescent sandwich immunoassay incorporating bovine anti-IL-8 specific antibodies as capture and detection. Samples were quantitated off a standard curve generated from bovine IL-8 protein. The following parameters were assessed for qualification: (1) standard cure, (2) quality control samples, (3) quantifiable range (assay range), accuracy and precision, (4) dilutional linearity, and (5) selectivity. Detailed assay development information can be found in supplemental material (Supplemental File S1; https://doi.org/10.3168/jds.2019-16337). The intraand interassay coefficients of variation for the assay were $<5$ and $6.5 \%$, respectively. 
For each cow, rectal temperature (RT) was measured at the blood collection time points. Body condition score (Edmonson et al., 1989) and BW were recorded weekly after the morning milking from calving to 30 DIM, and every other week from 45 to 90 DIM. Vaginal discharge was evaluated in all study cows at $3,7,14$, and 28 DIM using the Metricheck device (Metricheck, SimcroTech, Hamilton, New Zealand). Additionally, milk samples were collected for each cow into tubes containing 2-bromo-2-nitro-1,3-propanediol preservative during the morning milking daily from 1 to 6 DIM, and weekly from 7 to 28 DIM. Milk samples were submitted to a commercial laboratory (Dairy One Cooperative Inc., Ithaca, NY) for evaluation of percentage fat, protein, lactose, and SCC.

\section{Evaluation of the Peripheral Response to Insulin and Glucose Disappearance}

The peripheral response to glucose and insulin was evaluated using an intravenous glucose tolerance test (IVGTT) and intravenous insulin challenge test (IVICT) in a subgroup of cows $(n=20 /$ treatment $)$. Longterm 16-Ga catheters (Mila International Inc., Florence, KY) were placed into the jugular vein at 9 DIM. Intravenous glucose tolerance test and IVICT were performed on DIM 10 and 11, respectively. Cows were fasted for $3 \mathrm{~h}$ before each test, and tests were performed right after the morning milking. For the IVGTT, cows were infused with $0.25 \mathrm{~g} / \mathrm{kg}$ of BW of glucose (dextrose $50 \%$, wt/vol; Phoenix Scientific Inc., St. Joseph, MO) followed by $20 \mathrm{~mL}$ of sterile saline solution. For the IVICT, cows were infused with $0.2 \mathrm{IU}$ of insulin $/ \mathrm{kg}$ of BW (Sigma-Aldrich, St. Louis, MO) followed by $20 \mathrm{~mL}$ of sterile saline solution. Blood was sampled at $-15,0$, $10,20,30,45,60,90$, and 120 min relative to glucose or insulin infusion. In both tests, the catheters were flushed between sampling points with sterile saline solution containing $10 \mathrm{IU}$ of sodium heparin $/ \mathrm{mL}$ (Sagent, Schaumburg, IL) to avoid clotting. The initial $3 \mathrm{~mL}$ of blood drawn from the catheter at every sampling point was discharged before the sample was collected to avoid dilution. Blood was collected into evacuated tubes containing lithium heparin (Greiner Bio-One, Monroe, NC). Samples were placed on ice immediately and centrifuged within $1 \mathrm{~h}$ of collection as described above. Concentrations of glucose, insulin, and fatty acids (i.e., IVICT only) were evaluated as described above.

\section{Liver Biopsy}

Liver tissue was taken from the same subgroup of cows ( $\mathrm{n}=20 /$ treatment) selected for IVGTT and IV-
ICT at 14 DIM. Briefly, cow's hair was clipped on the right side at the 11th intercostal space. Ultrasonography (Ibex Pro, E.I. Medical Imaging, Loveland, CO) was performed to confirm the location of the liver and to avoid large hepatic blood vessels. The skin was disinfected thrice with iodine $(7.5 \% \mathrm{vol} / \mathrm{vol}$; VetOne, Boise, ID) and once with ethanol ( $70 \% \mathrm{vol} / \mathrm{vol}$; VetOne). Local anesthesia was performed using lidocaine (2\% lidocaine hydrochloride, MWI, Boise, ID). Approximately 10 min after the injection of lidocaine, the skin was punctured with a scalpel and a stainless-steel trocar (31 $\mathrm{cm}$ long and $7.5 \mathrm{~mm}$ in diameter) was introduced to the abdominal cavity directing the trocar toward the left elbow and $\sim 2$ g of liver tissue was harvested. The incision was closed with surgical staples (3M Precise, St. Paul, MN) and coated with aluminum spray bandage. Liver tissue samples were blotted on sterile gauze to remove blood and fixed in 10\% neutral buffered formalin for subsequent paraffin embedding and histological evaluation.

\section{Analysis of Liver Cell Proliferation and Apoptosis}

Liver Cell Apoptosis. Four-micrometer-thick sections of formalin-fixed/paraffin-embedded liver biopsies were used for terminal deoxynucleotidyl transferase dUTP nick end labeling (TUNEL) analysis. After deparaffinization in xylene and rehydration in graded ethanol, antigen retrieval was performed by incubating slides in heated citrate buffer (0.01 mol/L, pH 6.0) for $8 \mathrm{~min}$ following by cooling down in tap water for $10 \mathrm{~min}$. Endogenous peroxidase activity was quenched with $0.3 \%$ hydrogen peroxide in distilled water for 10 min. Then, the endogenous avidin/biotin were blocked with avidin/biotin blocking kit (Invitrogen, Carlsbad, CA) according to the manufacturer's instruction. For easy handling and minimizing variation, slides of multiple cases were processed in a batch with MicroProbe System (Fisher Scientific, Hampton, NH) and PBST $(0.05 \%$ Tween 20$)$ was used for washing throughout the procedure. After washing in PBST for 2 times (5 min each), apoptotic cells were detected using DeadEnd Colorimetric TUNEL System (Promega, Madison, WI). The sections were incubated with biotinylated nucleotide mix for $1.5 \mathrm{~h}$ at $37^{\circ} \mathrm{C}$ in a humid chamber. Nova Red (Vector Laboratories, Burlingame, CA) was used as chromogen to visualize antigen localization, and the sections were lightly counterstained with hematoxylin. Bovine tissue microarray with known apoptosis were used for protocol validation. Immunohistochemistry results were examined by Olympus AX 70 compound microscope equipped with MicroFire camera and PictureFrame for image processing and capture (Optronics, Goleta, CA). 
Liver Cell Proliferation. Formalin fixed, paraffin embedded tissue blocks were processed for Ki-67 antigen detection by immunohistochemistry staining at the Animal Health Diagnostic Center at Cornell University using an automated immunohistochemistry stainer (Leica Bond Max, Leica Biosystems, Buffalo Grove, IL). All steps for the immunohistochemistry staining were performed directly on the stainer. Slides were dewaxed (\#AR9222, Leica Bond Dewax solution) and then processed for heat epitope retrieval for 30 min (\#AR9961, Leica Bond Epitope Retrieval solution 1) followed by incubation with the primary antibody, mouse monoclonal anti-human KI67, clone MIB-1 (\#M7240, DakoCytomation, Carpinteria, CA) for $60 \mathrm{~min}$. Next Powervision-AP-Anti-Mouse IgG (\#PV6110, Leica Powervision Product) was applied to the slides for $30 \mathrm{~min}$ followed by the Red Detection (\#DS9390, Leica Bond Refine Red Detection Kit) for 15 min. Lastly, hematoxylin (\#DS9390, Leica Bond Refine Red Detection Kit) was applied to the slides for 5 min and coverslipped.

Quantification of Immunohistochemistry. Quantification of apoptotic cells and Ki-67 antigen expressing cells was done using a proprietary algorithm (IHC Nuclear, v1, Leica Aperio, Gmbh, Buffalo Grove, IL) with settings previously optimized using a tissue microarray of 20 normal bovine tissues, including liver. Supplemental Figure S1 (https://doi.org/10.3168/ jds.2019-16337) illustrates the comparison between a cow's liver section with high counts of positive hepatocyte nuclei versus a cow with low counts of positive hepatocyte nuclei for both assays, TUNEL and Ki-67.

\section{Liver Tissue Triglyceride Measurement}

Liver triglycerides (TG) were measured using the Folch extraction method (Folch et al., 1957) followed by a modified colorimetric assay based on Hantzsch condensation for estimating serum TG (Fletcher, 1968; Foster and Dunn, 1973). Briefly, samples were weighed $(0.15 \mathrm{~g})$ and extracted using chloroform:methanol (2:1 $\mathrm{vol} / \mathrm{vol}$ ). Following homogenization and centrifugation, extracted samples were mixed with aluminum oxide and saponified using $5 \% \mathrm{KOH}$ diluted in isopropanoldouble-distilled $\mathrm{H}_{2} \mathrm{O}$ (40:60 vol/vol). Sodium metaperiodate and acetylacetone reagents were added and samples were read at $405 \mathrm{~nm}$. Fatty liver was categorized based on the percentage of liver TG into normal liver ( $<1 \%$ of liver TG), and mild ( $1-5 \%$ of liver TG), moderate (5-10\% of liver TG), and severe fatty liver $(>10 \%$ of liver TG), as previously described (Bobe et al., 2004).

\section{Disease Definitions}

Dystocia was defined as a calving that required assistance from farm personnel. Retained placenta (RP) was defined as cows that failed to release the fetal membranes within $24 \mathrm{~h}$ after calving (Kelton et al., 1998). Diagnosis of metritis, puerperal metritis, and endometritis were performed by research personnel based on evaluation of vaginal mucus retrieved using a Metricheck device. Vaginal discharge was scored using a modified 0 to 5 scale $(0=$ no secretion material retrieved; $1=$ clear mucus; $2=$ clear mucus with flecks of pus; $3=$ mucopurulent discharge containing $<50 \%$ of pus; $4=$ mucopurulent discharge containing $\geq 50 \%$ of pus; $5=$ watery, red-brown, fetid vaginal discharge). Cows with a score $=5$ at 3,7 , or 14 DIM were considered to have clinical metritis. Puerperal metritis was defined as cows having clinical metritis with $\mathrm{RT}>39.5^{\circ} \mathrm{C}$ (Sheldon et al., 2006). Cows with a score $\geq 3$ at 28 DIM were considered to have clinical endometritis. Displaced abomasum diagnosis was made by researchers and confirmed by veterinarians. Lameness was defined as cows with clinical manifestation of abnormal locomotion detected by researchers and farm personnel. Clinical ketosis was detected by researchers and farm personnel and defined as cows with decreased milk production, reduced feed intake, low rumen fill, weakness, dullness, depression, with/without ketone odor in breath, and high blood concentration of BHB. Hyperketonemia was defined as plasma BHB concentration $\geq 1.4 \mathrm{mmol} / \mathrm{L}$ from blood samples collected from 1 to 28 DIM. Clinical mastitis was evaluated during the first 30 DIM and defined as the presence of abnormal milk, such as watery appearance, flakes, and clots in milk during forestripping detected at each milking by trained farm employees. Subclinical mastitis (SCM) was defined as cows detected with a SCS $\geq 4$ at 7, 14, 21 , or 28 DIM.

\section{Calculations and Data Analysis}

Energy balance (EBAL) was calculated based on the weekly energy intake: $\mathrm{NE}_{\mathrm{L}}$ intake $=$ (weekly $\mathrm{DMI} \times$ diet energy density); maintenance requirements: $\mathrm{NE}_{\mathrm{L}}$ for maintenance $=\left(0.08 \times \mathrm{BW}^{0.75}\right)$; and milk energy output: $\mathrm{NE}_{\mathrm{L}}$ for milk production $=$ \{weekly milk yield $\times[(0.0929 \times$ fat $\%)+(0.0563 \times$ protein $\%)+(0.0395$ $\times$ lactose \%)]\}. Energy balance was calculated (NRC, 2001) as follows: $\mathrm{NE}_{\mathrm{L}}$ balance (Mcal) $=\mathrm{NE}_{\mathrm{L}}$ intake - $\left(\mathrm{NE}_{\mathrm{L}}\right.$ for milk production $+\mathrm{NE}_{\mathrm{L}}$ for maintenance). Weekly ECM yield was calculated (Bernard, 1997) from 0 to 30 DIM as follows: ECM $(\mathrm{kg})=[(0.3246 \times$ milk yield $)+(12.86 \times$ fat yield $)+(7.04 \times$ protein 
yield)]. Weekly 3.5\% FCM yield was calculated (Nordlund, 1987) from 0 to 30 DIM as follows: FCM $(\mathrm{kg})$ $=[(0.4324 \times$ milk yield $)+(16.216 \times$ fat yield $)]$. Production efficiency was calculated based on milk yield, ECM, and DMI as follows: milk yield efficiency $(\mathrm{kg})=$ (milk yield/DMI); ECM yield efficiency $(\mathrm{kg})=(\mathrm{ECM} /$ DMI). Linear SCS was calculated (Schutz, 1994) as follows: $\mathrm{SCS}=\left\{\left[\ln \left(\mathrm{SCC} / 100 \times 10^{3}\right) / 0.693147\right]+3\right\}$.

Insulin sensitivity was evaluated using the following insulin sensitivity indexes: quantitative insulin sensitivity check index (QUICKI) $=\{1 /[\log$ insulin $(\mu \mathrm{U} / \mathrm{mL})+\log$ glucose $(\mathrm{mg} / \mathrm{dL})]\}$, according to Katz et al. (2000); revised QUICKI (RQUICKI) $=\{1 /[\log$ glucose $(\mathrm{mg} / \mathrm{dL})+\log$ insulin $(\mu \mathrm{U} / \mathrm{mL})+\log$ fatty acids $(\mathrm{mmol} / \mathrm{L})]\}$, according to (Perseghin et al., 2001; Holtenius and Holtenius, 2007); revised QUICKI including BHB (RQUICKI $\left.\mathbf{B H B}_{\mathrm{BHB}}\right)=\{1 /[\log$ glucose $(\mathrm{mg} /$ $\mathrm{dL})+\log$ insulin $(\mu \mathrm{U} / \mathrm{mL})+\log$ fatty acids $(\mathrm{mmol} / \mathrm{L})$ $+\log$ BHB (mmol/L)]\}, according to (Balogh et al., 2008); and the homeostatic model assessment of insulin resistance $($ HOMA-IR $)=\{[$ glucose $(\mathrm{mmol} / \mathrm{L}) \times$ insulin $(\mu \mathrm{U} / \mathrm{mL})] / 22.5\}$, according to (Muniyappa et al., 2008). Moreover, plasma concentrations of glucose, insulin, and fatty acids (i.e., IVICT only) from IVGTT and IVICT were used to create response curves. The positive incremental area under the curve (AUC) after glucose or insulin infusion of glucose, insulin, and fatty acids was calculated in SAS, correcting for baseline based on the trapezoidal method as previously described (Cardoso et al., 2011).

Descriptive statistics were performed in JMP Pro 11 (SAS Institute Inc., Cary, NC), using the ANOVA and chi-squared functions for continuous and categorical data, respectively. Collinearity among predictor variables was assessed using the multivariate procedure in JMP. We detected a collinearity issue between the variables parity and $\mathrm{BW}$ at enrollment $(\mathrm{r}=0.82 ; P<$ $0.001)$. We offered to the models the variables parity and BW at enrollment separately, and the one that yielded the minimum Akaike information criterion was chosen. Therefore, for milk production, ECM, FCM, DMI, production efficiency, and EBAL analyses, BW at enrollment was included in all models. Enrollment block was included as a random effect. For analyses of repeated measurements, we used general mixed linear models with the MIXED procedure of SAS (version 9.4, SAS/STAT, SAS Institute Inc.). The independent variables offered to the models were treatment, time, BW at enrollment, BCS at enrollment, RT at enrollment, dystocia, stillbirth, subset (cows that underwent IVGTT/IVICT and liver biopsy), time from calving to treatment (enrollment), placenta present at enrollment, and previous days carry calf. Two-way and 3-way interaction terms between independent variables were offered to the models. For hemogram parameters, metabolites, and hormones concentrations, baseline values were treated as covariate variables. Normality and homoscedasticity of residuals were assessed using residual plots. Continuous data with residuals not normally distributed were $\log _{10}$ transformed. Several covariance structures were tested (unstructured, autoregressive 1, compound symmetry), and the one with the minimum Akaike information criterion was chosen. For all models, Dunnett's significance test for multiple comparisons was used. Data are reported as least squares means \pm standard error of the mean unless otherwise stated.

The effect of treatment on binary response variables was analyzed by logistic regression using the GLIMMIX procedure of SAS and the fixed effects of treatment, parity, BCS at enrollment, RT at enrollment, dystocia, stillbirth, time from calving to treatment, placenta present at enrollment, and the interaction term treatment by parity were included as independent variables in the statistical models. Dunnett's significance test for multiple comparisons was used. A categorical variable named "diseases combined" was created to evaluate the effect of treatment on the proportion of cows affected by common diseases during the first 30 DIM; the following diseases were combined for analysis: RP, metritis, puerperal metritis, endometritis, DA, CK, lameness, CM, and SCM. In addition, CK and DA were also combined for analysis.

The effect of treatment on the hazard of pregnancy and herd removal during the first 180 DIM were analyzed by Cox's proportional hazard using the PHREG procedure in SAS. Variables offered to the models included treatment, parity, BCS at enrollment, dystocia, stillbirth, time from calving to treatment, placenta present at enrollment, and interactions. To illustrate the effect of treatment on reproductive performance and herd removal, Kaplan-Meier survival analysis was carried out using MedCalc version 11.5.1.0 software (MedCalc Software, Ostend, Belgium).

For all models, variables and their respective interaction terms were removed from the models in a backward stepwise elimination procedure when $P>0.15$. Significances were considered when $P \leq 0.05$ or a trend if $0.05<P \leq 0.10$.

\section{RESULTS}

\section{Lactation Performance, DMI, and Energy Balance}

To test for the genetic merit of milk production between treatment groups, genetic differences in total pounds of milk produced during a 305-d lactation (CLARIFIDE test) was evaluated. No significant differences $(P=0.65)$ were observed among groups. 


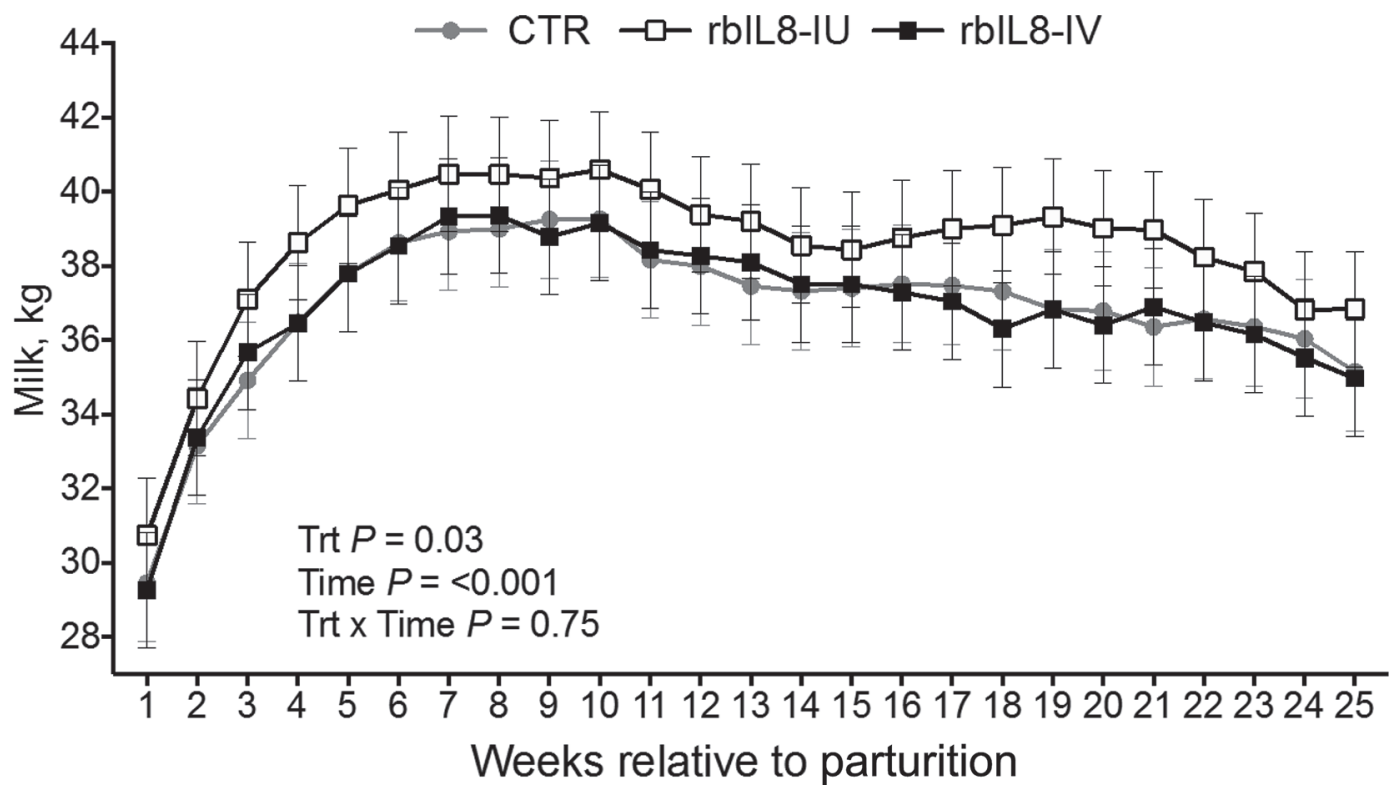

Figure 1. Weekly milk yield for the first 25 wk of lactation of cows treated with recombinant bovine interleukin-8 intrauterine (rbIL8-IU, $\mathrm{n}$ $=70$ ), intravenously (rbIL8-IV, $\mathrm{n}=70$ ), and controls (CTR, $\mathrm{n}=70$ ). Dunnett's significance test for multiple comparisons was used: CTR versus rbIL8-IU, $P=0.05$; CTR versus rbIL8-IV, $P=0.99$. Results are presented as LSM \pm SEM. Trt $=$ treatment.

The effects of rbIL-8 treatment on weekly milk averages (first 25 wk of lactation), ECM, and FCM yields (first 4 wk of lactation) are presented in Table 3 and Figures 1 and 2. Cows treated with rbIL8-IU produced $1.6,3.1$, and $3.5 \mathrm{~kg} / \mathrm{d}$ more milk $(P=0.03), \operatorname{ECM}(P$ $=0.006)$, and FCM $(P=0.004)$ yields when compared with CTR cows; no differences were observed between the rbIL8-IV and CTR groups.

Milk fat, protein, and lactose percentage were not affected by treatment (Table 3). However, cows treated with rbIL8-IU produced 0.15 and $0.08 \mathrm{~kg} / \mathrm{d}$ more fat $(P=0.007)$ and lactose $(P=0.07)$, respectively, when compared with control cows, but no differences were observed between the rbIL8-IV and CTR group. Milk protein yield and SCS were not affected by rbIL-8 treatment (Table 3).

Dry matter intake during the first 4 wk of lactation is presented in Table 3 and Figure 2. We observed that cows treated with rbIL8-IU consumed $1.1 \mathrm{~kg} / \mathrm{d}$ more DM $(P=0.03)$ when compared with CTR cows, but

Table 3. Weekly milk yield for the first 25 wk postpartum, and production and feed intake responses during the first 4 wk of lactation of cows treated with recombinant bovine interleukin-8 intrauterine (rbIL8-IU, $\mathrm{n}=70)$, intravenously $(\mathrm{rbIL} 8-\mathrm{IV}, \mathrm{n}=70)$, and controls $(\mathrm{CTR}, \mathrm{n}=70)^{1}$

\begin{tabular}{|c|c|c|c|c|c|}
\hline \multirow[b]{2}{*}{ Item } & \multicolumn{3}{|c|}{ Treatment group } & \multicolumn{2}{|c|}{$P$-value ${ }^{1}$} \\
\hline & $\begin{array}{c}\text { CTR } \\
(\mathrm{LSM} \pm \mathrm{SEM})\end{array}$ & $\begin{array}{c}\text { rbIL8-IU } \\
(\mathrm{LSM} \pm \mathrm{SEM})\end{array}$ & $\begin{array}{c}\text { rbIL8-IV } \\
(\mathrm{LSM} \pm \mathrm{SEM})\end{array}$ & $\begin{array}{l}\text { CTR vs. } \\
\text { rbIL8-IU }\end{array}$ & $\begin{array}{l}\text { CTR vs. } \\
\text { rbIL8-IV }\end{array}$ \\
\hline ECM yield, $\mathrm{kg} / \mathrm{d}$ & $42.9 \pm 0.9$ & $46.1 \pm 0.9$ & $43.7 \pm 0.9$ & 0.006 & 0.69 \\
\hline FCM yield, $\mathrm{kg} / \mathrm{d}$ & $44.3 \pm 0.9$ & $47.8 \pm 0.9$ & $45.2 \pm 0.9$ & 0.004 & 0.64 \\
\hline Fat vield, $\mathrm{kg} / \mathrm{d}$ & $1.78 \pm 0.03$ & $1.93 \pm 0.03$ & $1.83 \pm 0.03$ & 0.005 & 0.47 \\
\hline Fat, $\%$ & $4.81 \pm 0.06$ & $4.88 \pm 0.06$ & $4.82 \pm 0.06$ & 0.58 & 0.98 \\
\hline Protein, $\%$ & $3.76 \pm 0.04$ & $3.75 \pm 0.04$ & $3.75 \pm 0.04$ & 0.90 & 0.93 \\
\hline Lactose, \% & $4.60 \pm 0.02$ & $4.61 \pm 0.02$ & $4.58 \pm 0.02$ & 0.94 & 0.42 \\
\hline DMI, kg/d & $18.8 \pm 0.3$ & $19.9 \pm 0.3$ & $19.3 \pm 0.3$ & 0.03 & 0.39 \\
\hline Energy balance, Mcal/d & $-15.2 \pm 0.6$ & $-15.2 \pm 0.6$ & $-14.6 \pm 0.6$ & 0.99 & 0.66 \\
\hline Milk yield:DMI & $2.0 \pm 0.03$ & $2.0 \pm 0.03$ & $1.9 \pm 0.03$ & 0.79 & 0.29 \\
\hline ECM:DMI & $2.4 \pm 0.03$ & $2.4 \pm 0.03$ & $2.3 \pm 0.03$ & 0.99 & 0.41 \\
\hline
\end{tabular}

${ }^{1}$ Dunnett's significance test for multiple comparisons was used.

${ }^{2}$ Milk yield for the first $25 \mathrm{wk}$ of lactation. 


\section{$\rightarrow$ CTR $\rightarrow \square$ rbIL8-IU $\rightarrow$ rbIL8-IV}
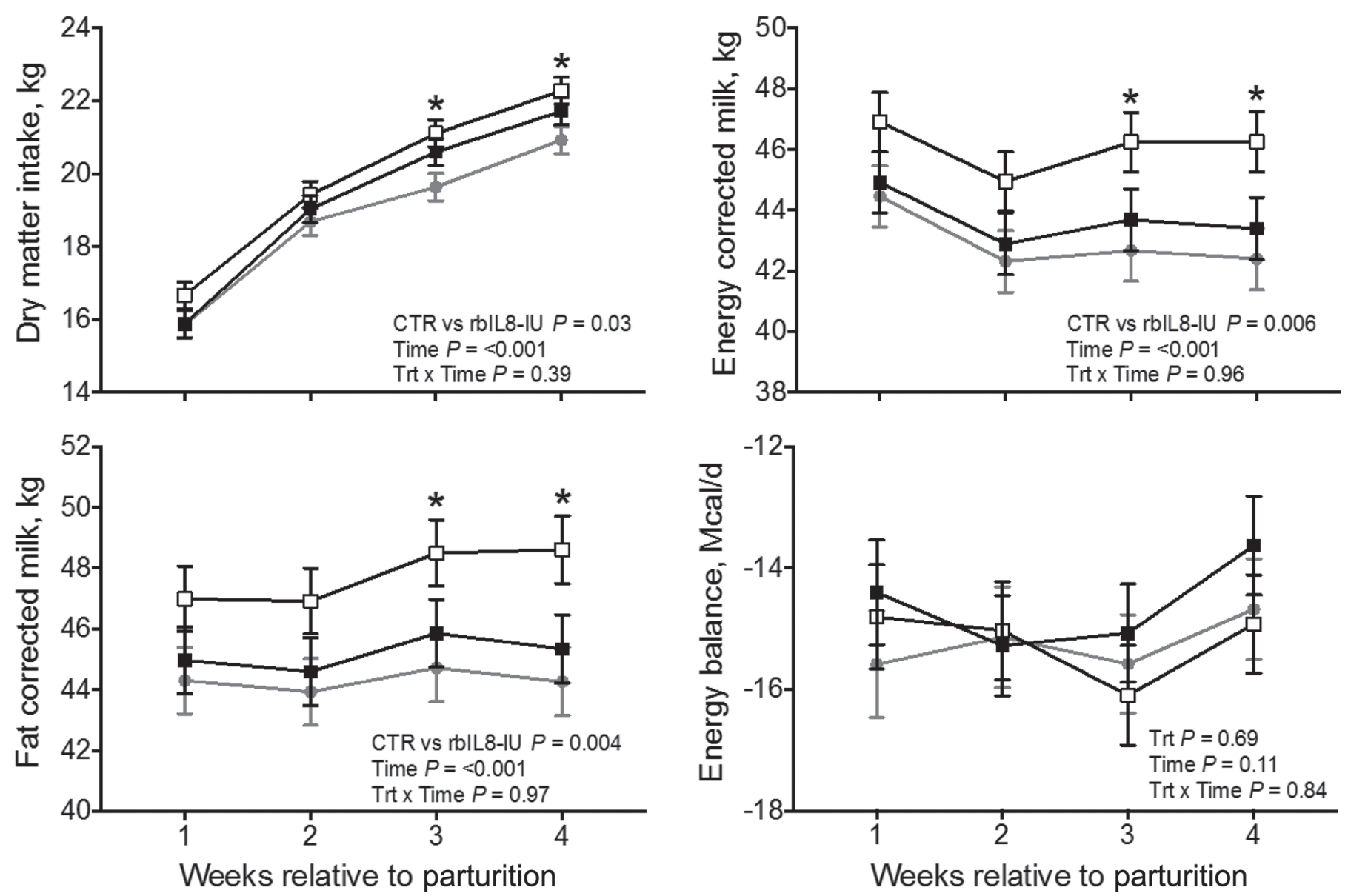

Figure 2. Dry matter intake, ECM, FCM, and energy balance for the first $4 \mathrm{wk}$ of lactation of cows treated with recombinant bovine interleukin-8 intrauterine (rbIL8-IU, $\mathrm{n}=70$ ), intravenously (rbIL8-IV, $\mathrm{n}=70$ ), and controls $(\mathrm{CTR}, \mathrm{n}=70$ ). Results are presented as LSM \pm SEM. ${ }^{*} P<0.05$ (CTR vs. rbIL8-IU). Trt $=$ treatment.

no differences were observed between the rbIL8-IV and CTR groups. Ratios of milk production and ECM to DMI, and EBAL were not affected by treatment (Table $3)$.

\section{Plasma Metabolites, Hormones, Hepatic Enzymes, and IL-8 Concentrations}

Plasma concentrations of fatty acids, BHB, glucose, cholesterol, total bilirubin, urea, lactate albumin, total protein, alanine aminotransferase, aspartate aminotransferase, gamma glutamyl transferase, alkaline phosphatase, and haptoglobin were not affected by treatment (Table 4, Figure 3, and Supplemental Figures S2 and S3, https://doi.org/10.3168/jds.2019-16337). Treatment did not affect plasma levels of insulin, GH, or IGF-1 (Table 4 and Figures 3 and 4). Moreover, plasma IL- 8 levels were not altered by rbIL- 8 treatment (Table 4 and Figure 5).

\section{$B C S$ and $B W$ Loss}

The effects of treatment on BCS and BW loss during the first $90 \mathrm{~d}$ of lactation are illustrated in Figure 6. No differences were observed between treatment groups.

\section{Liver Triglyceride Levels, Cell Proliferation, and Cell Apoptosis}

Liver TG levels were affected $(P=0.01)$ by rbIL8 treatment. Cows treated with rbIL8-IU or rbIL8-IV had higher liver TG concentrations when compared with CTR cows (Figure 7). Liver cell proliferation was not affected by treatment. Cows treated with rbIL8-IV 
cows had $(P=0.003)$ a higher number of apoptotic cells than CTR cows (Figure 7). However, the ratio liver cell apoptosis to cell proliferation was not affected $(P=0.31)$ by treatment (Figure 7$)$. Furthermore, no differences were observed between treatment groups when cows were classified based on TG levels in mild and moderate fatty liver (no cows were detected with normal or severe fatty liver; Figure 7).

\section{IVGTT, IVICT, and Insulin Sensitivity Indexes}

For the IVGTT, glucose and insulin AUC at $120 \mathrm{~min}$ from glucose infusion were not affected by treatment (Figure 8A). We also evaluated the glucose and insulin AUC at 10, 20, 30, 45, and 60 min from glucose infusion and no differences $(P>0.38)$ were detected between treatment groups (data not shown). For the IVICT, glucose and fatty acid AUC were not affected by treatment (Figure 8B). Moreover, QUICKI, RQUICKI, RQUICKI $_{\mathrm{BHB}}$, and HOMA-IR did not differ between treatment groups (Figure 9).

\section{Hemogram Parameters and Rectal Temperature}

Results of white blood cells, PMN, lymphocytes, monocytes, red blood cells, and percentage hematocrit are illustrated in Supplemental Figure S4 (https://doi .org/10.3168/jds.2019-16337). No differences were observed on white blood cells, PMN, lymphocytes, and monocytes numbers between treatment groups. However, rbIL- 8 treatment did affect $(P=0.002)$ red blood cell numbers. Relative to CTR cows, rbIL8-IU cows had lower red blood cell numbers and no differences were observed between rbIL8-IV and CTR groups. Additionally, we observed that cows treated with rbIL8-IU tended to have lower percentage hematocrit when compared with CTR cows and no differences were observed between rbIL8-IV and CTR cows. Treatment did not affect $(P=0.34)$ RT during the first 4 wk postpartum $(\mathrm{CTR}=38.6 \pm 0.03 ;$ rbIL8-IU $=38.7 \pm 0.03 ;$ rbIL8-IV $\left.=38.7 \pm 0.03^{\circ} \mathrm{C}\right)$.

\section{Health Disorders}

Treatment did not alter the incidence of RP, metritis, puerperal metritis, endometritis, DA, CK, CM, SCM, and lameness (Table 5). Cows treated with rbIL8-IU tended to have lower odds of developing HYK when compared with CTR cows (Table 5). Moreover, rbIL8-IU cows had lower odds of developing CK and DA combined than CTR cows (Table 5). Additionally, cows treated with rbIL8-IU had lower odds of being diagnosed with 1 or more diseases when compared with CTR cows (Table 5).

Table 4. Plasma metabolites, liver enzymes, IL-8, and hormone concentrations during the first 4 wk of lactation of cows treated with recombinant bovine interleukin-8 intrauterine ( $\mathrm{rbIL} 8-\mathrm{IU}, \mathrm{n}=70$ ), intravenously (rbIL8-IV, $\mathrm{n}=70$ ), and controls $(\mathrm{CTR}, \mathrm{n}=70)$

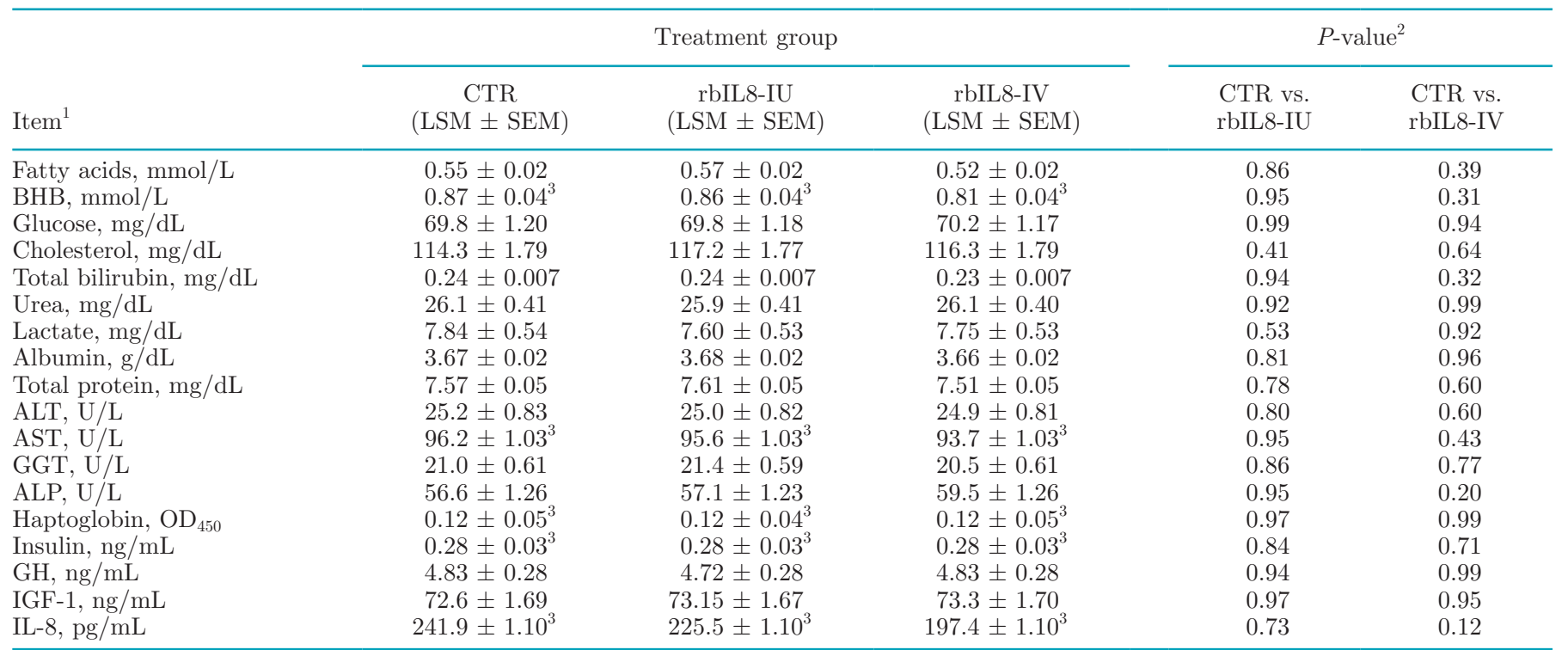

\footnotetext{
${ }^{1} \mathrm{ALT}=$ alkaline phosphatase; $\mathrm{AST}=$ aspartate aminotransferase; $\mathrm{GGT}=$ gamma glutamyl transferase; $\mathrm{ALP}=$ alanine aminotransferase; $\mathrm{OD}_{450}$ $=$ optical density at $450 \mathrm{~nm} ; \mathrm{GH}=$ growth hormone.

${ }^{2}$ Dunnett's significance test for multiple comparisons was used.

${ }^{3} \log _{10}$ back-transformed concentrations.
} 


\section{Removal from the Herd and Reproductive Performance}

Treatment did not alter $(P=0.23)$ the hazard of culling during the first 180 DIM (rbIL8-IU, hazard ratio: $0.79,95 \%$ CI: 0.54 to 1.63 ; rbIL8-IV, hazard ratio: 0.94 , 95\% CI: 0.65 to 1.38; Supplemental Figure S5A, https:/ /doi.org/10.3168/jds.2019-16337). Moreover, treatment did not alter $(P=0.47)$ the hazard of pregnancy during the first 180 DIM (rbIL8-IU, hazard ratio: 0.79, 95\% CI: 0.54 to 1.63 ; rbIL8-IV, hazard ratio: $0.94,95 \%$ CI: 0.65 to 1.38; Supplemental Figure S5B, https://doi .org/10.3168/jds.2019-16337). The median calving-toconception interval for CTR, rbIL8-IU, and rbIL8-IV was $70.5,86$, and $80 \mathrm{~d}$, respectively.

\section{DISCUSSION}

This study was conducted to explore underlying mechanisms by which rbIL- 8 treatment increases milk production in Holstein cows. In line with our previous studies (Zinicola et al., 2019a), the IU administration of rbIL-8 within $12 \mathrm{~h}$ of parturition significantly increased milk, FCM, and ECM yields in Holstein cows with no changes in BCS. Furthermore, intravenous administration of rbIL-8 did not suppress DMI or milk production and was not associated with any negative side effects. Moreover, BW and EBAL were not affected by rbIL- 8 treatment. Interestingly, the administration of rbIL8 IU resulted in higher DMI during the first 4 wk postpartum. Treatment with rbIL8-IU tended to reduce the
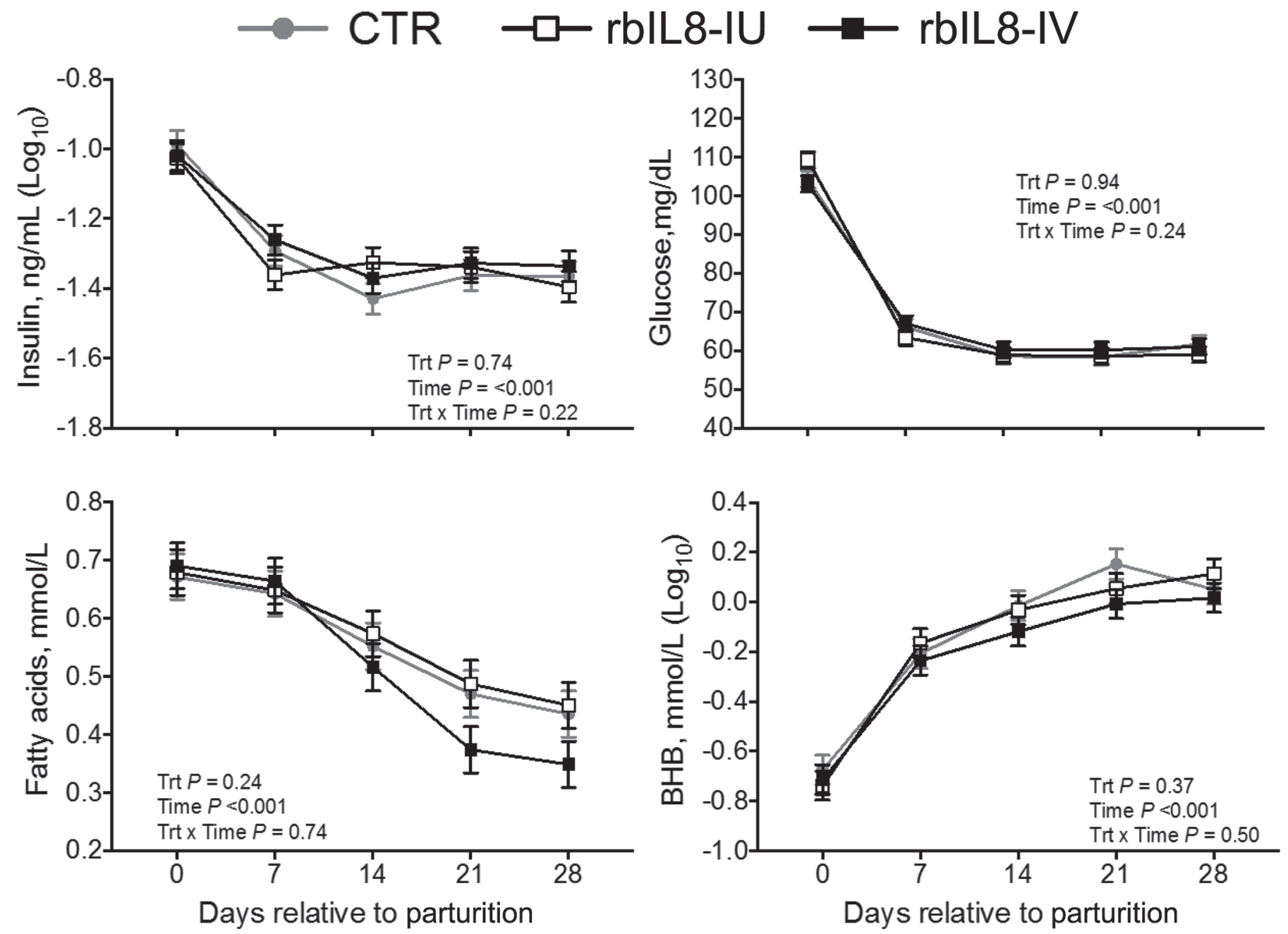

Figure 3. Plasma concentrations of insulin, glucose, fatty acids, and BHB for the first 4 wk of lactation of cows treated with recombinant bovine interleukin-8 intrauterine (rbIL8-IU, $\mathrm{n}=70$ ), intravenously ( $\mathrm{rbIL} 8-\mathrm{IV}, \mathrm{n}=70$ ), and controls $(\mathrm{CTR}, \mathrm{n}=70)$. Results are presented as $\mathrm{LSM} \pm \mathrm{SEM}$. Trt $=$ treatment. 
incidence of HYK and reduced overall diseases when compared with CTR while not altering early lactation metabolism; none of the hormones and metabolites herein evaluated were affected by treatment. In addition, peripheral tissue insulin sensitivity was not altered by rbIL- 8 treatment. Therefore, it is likely that the observed long-term production responses following rbIL8-IU treatment are a result of increased DMI likely derived from improved overall health. In support of this notion, the ratio of milk and ECM to DMI was similar among treatment groups.

We have previously shown that cows that received a single IU administration of rbIL-8 shortly after parturition produced more milk during the first 6 mo of lactation with no changes on BCS (Zinicola et al., 2019a). Because cows treated with rbIL- 8 had similar BCS loss during the first 35 DIM compared with controls, it is plausible to propose that rbIL-8-treated cows had increased DMI during the same period. Unfortunately, in that study, it was not possible to measure DMI. In the present study, we confirmed that rbIL- 8 treated cows produced more milk, whereas no differences in BCS and BW loss were observed from placebo-treated animals. Importantly, we demonstrated for the first time that a single administration of rbIL8-IU in Holstein cows within $12 \mathrm{~h}$ of parturition was associated with increased DMI during the first 30 DIM. To the best of our knowledge, this is the first report to demonstrate an effect of rbIL- 8 treatment on DMI in an animal model. It is also unforeseen since other pro-inflammatory cytokines have been repeatedly associated with appetite suppression and in some reports with a drastic reduction in milk production (Langhans and Hrupka, 1999; Yuan et al., 2013).
A recent study evaluated the effects of recombinant bovine tumor necrosis- $\alpha$ (rbTNF- $\alpha$ ) treatment in dairy cows during the early lactation on DMI, metabolism, and milk production (Yuan et al., 2013). Cows that received rbTNF- $\alpha$ had significantly lower DMI, lower water intake, and produced significantly less milk when compared with controls. Insulin is one of the most important anorexigenic hormone acting on hypothalamus (Plum et al., 2005). In the study conducted by Yuan et al. (2013), rbTNF- $\alpha$ treatment did not alter the concentration of plasma insulin and dramatic changes on metabolism were not observed. These results reinforced the well-known potent anorexigenic effect of rbTNF- $\alpha$ acting directly in the hypothalamus (Romanatto et al., 2007). Moreover, rbTNF- $\alpha$ treatment increased plasma haptoglobin concentrations (Yuan et al., 2013). Interleukin-8 is also a potent pro-inflammatory chemokine capable of activating and attracting neutrophils, but the body of knowledge generated by our group over several different controlled trials (Bicalho et al., 2018; Zinicola et al., 2019a) indicates that the detrimental effects on appetite, metabolism, and health are not observed after a one-time IV or IU administration.

Lipopolysaccharide challenge models have been used in many different animal species to advance our understanding about the interaction of immunological responses and metabolism (Spurlock, 1997; Kvidera et al., 2017). Specifically, LPS challenge is associated with an increase in white blood cells, fever, an increase in acute-phase proteins, elevated inflammatory mediators, depressed appetite, and dramatic changes in metabolism (Mulligan et al., 2012; Dillingh et al., 2014; Kvidera et al., 2017). Recently, Kvidera et al. (2017) studied the whole-body glucose utilization following a

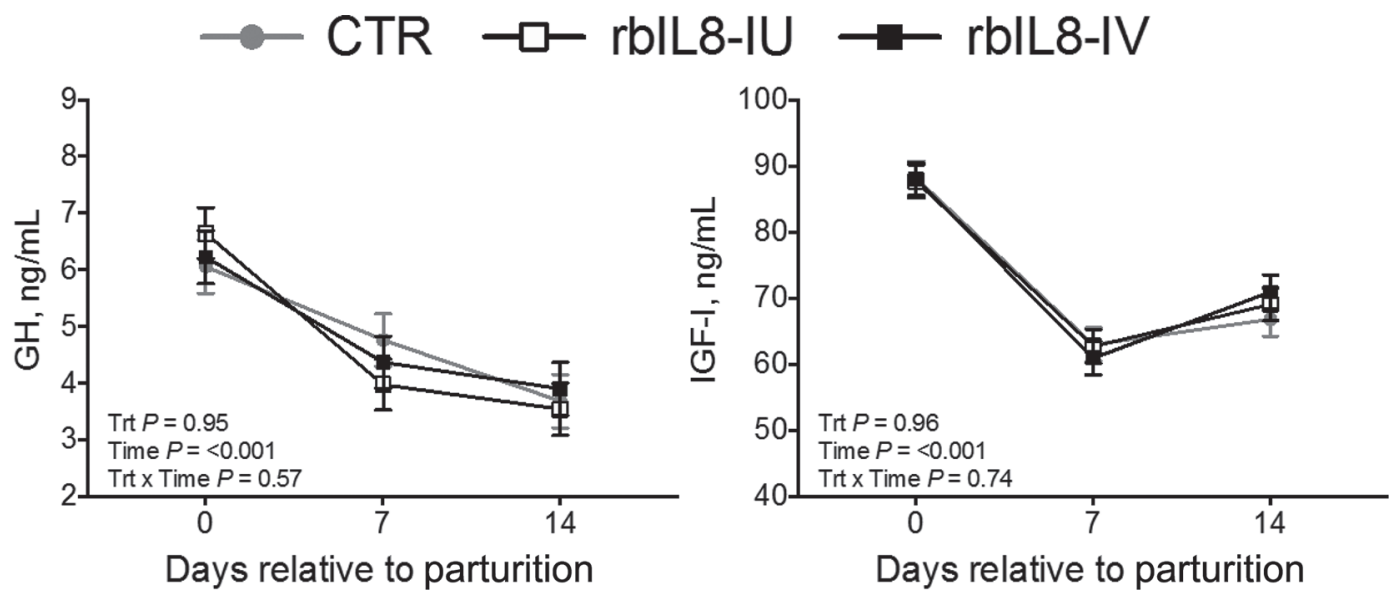

Figure 4. Plasma concentrations of growth hormone (GH) and IGF-I at 0, 7, and $14 \mathrm{~d}$ relative to parturition of cows treated with recombinant bovine interleukin-8 intrauterine (rbIL8-IU, $\mathrm{n}=70$ ), intravenously (rbIL8-IV, $\mathrm{n}=70$ ), and controls $(\mathrm{CTR}, \mathrm{n}=70)$. Results are presented as $\mathrm{LSM} \pm \mathrm{SEM}$. Trt $=$ treatment. 


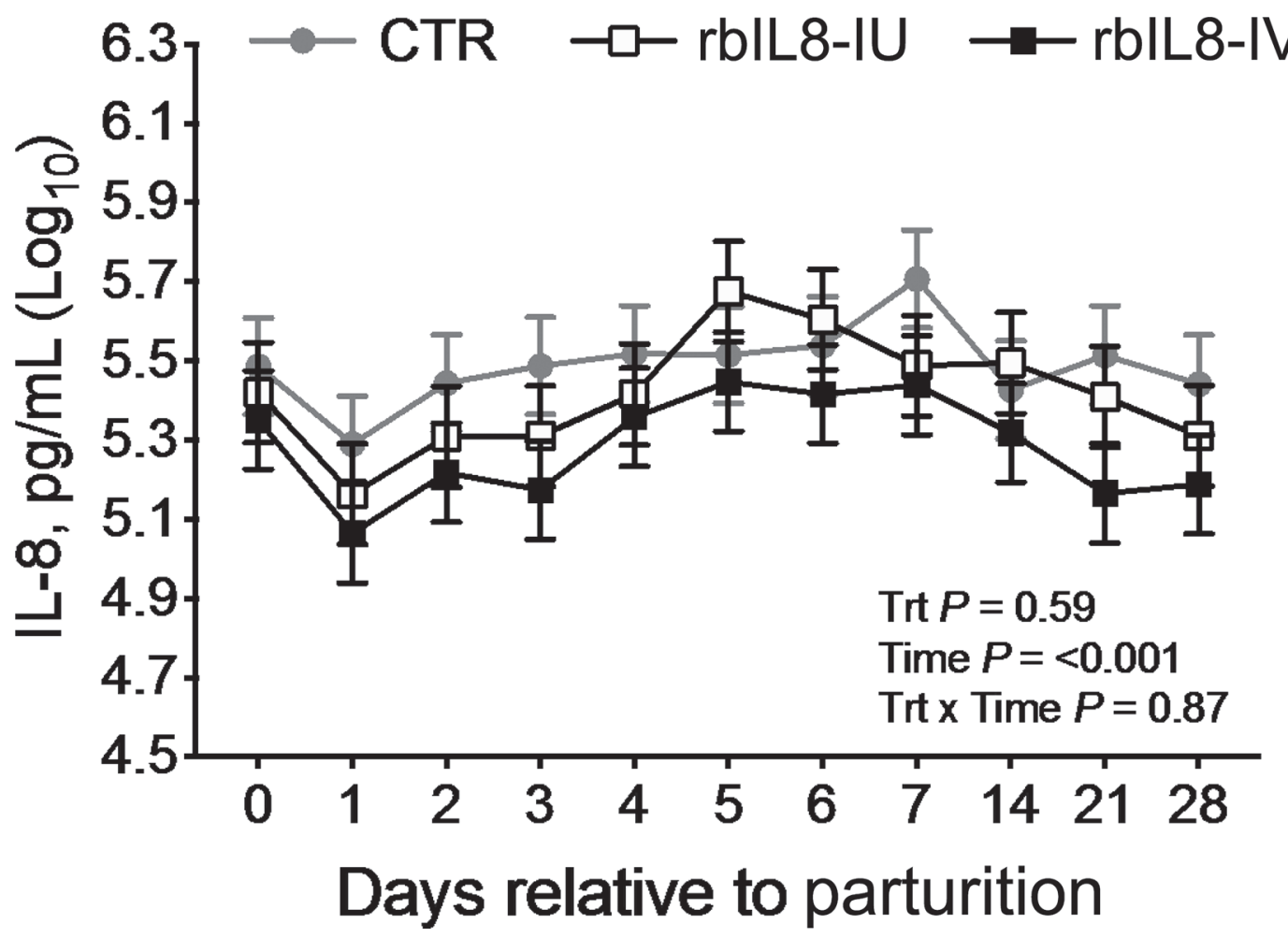

Figure 5. Daily plasma concentrations of bovine IL- 8 for the first 7 DIM and weekly until 28 DIM of cows treated with recombinant bovine interleukin-8 intrauterine (rbIL8-IU, $\mathrm{n}=70$ ), intravenously (rbIL8-IV, $\mathrm{n}=70)$, and controls $(\mathrm{CTR}, \mathrm{n}=70)$. Results are presented as LSM \pm SEM. Trt $=$ treatment.

single LPS bolus challenge while exploring the metabolic and production changes in mid-lactation Holstein cows. They observed that LPS challenge resulted in a quick increase in circulating glucose concentration, likely as a result of glycogenolysis, followed by a period of decreased glucose concentration. Because of LPS challenge, a dramatic and sustained increase in plasma insulin (6-fold increase) was reported. The increase in plasma insulin observed in that study likely redirected energy resources toward insulin dependent tissues, decreased gluconeogenesis, suppressed appetite, and halted lipolysis, which in combination with high levels of circulating pro-inflammatory cytokines would explain the resulting dramatic decrease in DMI and milk production. That metabolic milieu, which characterizes the metabolic changes of an animal with an activated immune system, was not observed in cows treated with rbIL8-IU or rbIL8-IV.

Like most cytokines, it was shown that endogenous IL- 8 is present at low concentrations in serum and has a short circulating half-life ( $\sim 4 \mathrm{~h}$; Martich et al., 1991). Degradation of IL-8 generally occurs following receptor internalization by neutrophils via proteolytic degradation by elastase (Holmes et al., 1991). Moreover, it has been proposed that erythrocytes might affect circulat- ing IL-8 levels through their Duffy antigen receptor for chemokines (DARC); a receptor with high affinity for ELR motif chemokines such IL-8 (Apostolakis et al., 2011). In the present study, rbIL-8 treatment did not alter plasma IL-8 levels. In contrast to these results, we have observed in a previous study that cows that received a low or high single dose of rbIL- 8 administered intrauterine within $12 \mathrm{~h}$ of parturition had higher levels of IL-8 at 3 d postpartum when compared with controls (Zinicola et al., 2019a). In that study, however, serum IL-8 concentrations were measured using a human ELISA kit and from a subset of cows (20/treatment group). In the current study, considering that plasma IL-8 levels were measured from a large sample size (70/ treatment group) and that a bovine immunoassay was used to quantify IL- 8 concentrations, we conclude that rbIL-8 treatment does not alter plasma IL-8 levels. These results suggest the following: (1) the observed increase in milk production and DMI as well as improved health following rbIL8-IU are a consequence of a local effect in the uterus, and (2) IL- 8 residues in meat and milk following a single administration of rbIL- 8 shortly after parturition are not expected.

We are not aware of any possible direct effect or mechanism that could link IL-8 with a central regula- 

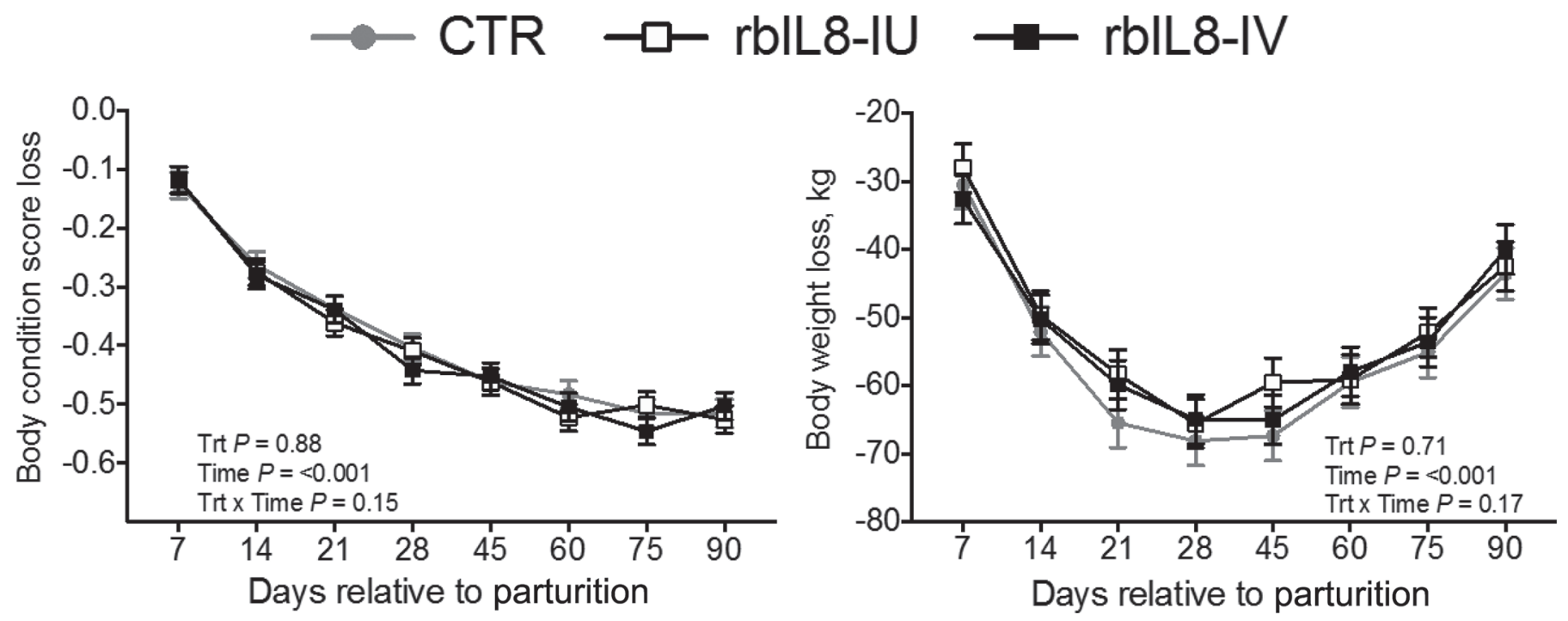

Figure 6. Body condition score loss and BW loss during the first $90 \mathrm{~d}$ of lactation of cows treated with recombinant bovine interleukin- 8 intrauterine (rbIL8-IU, $\mathrm{n}=70$ ), intravenously ( $\mathrm{rbIL} 8-\mathrm{IV}, \mathrm{n}=70$ ), and controls $(\mathrm{CTR}, \mathrm{n}=70)$. Results are presented as LSM \pm SEM. Trt $=$ treatment.
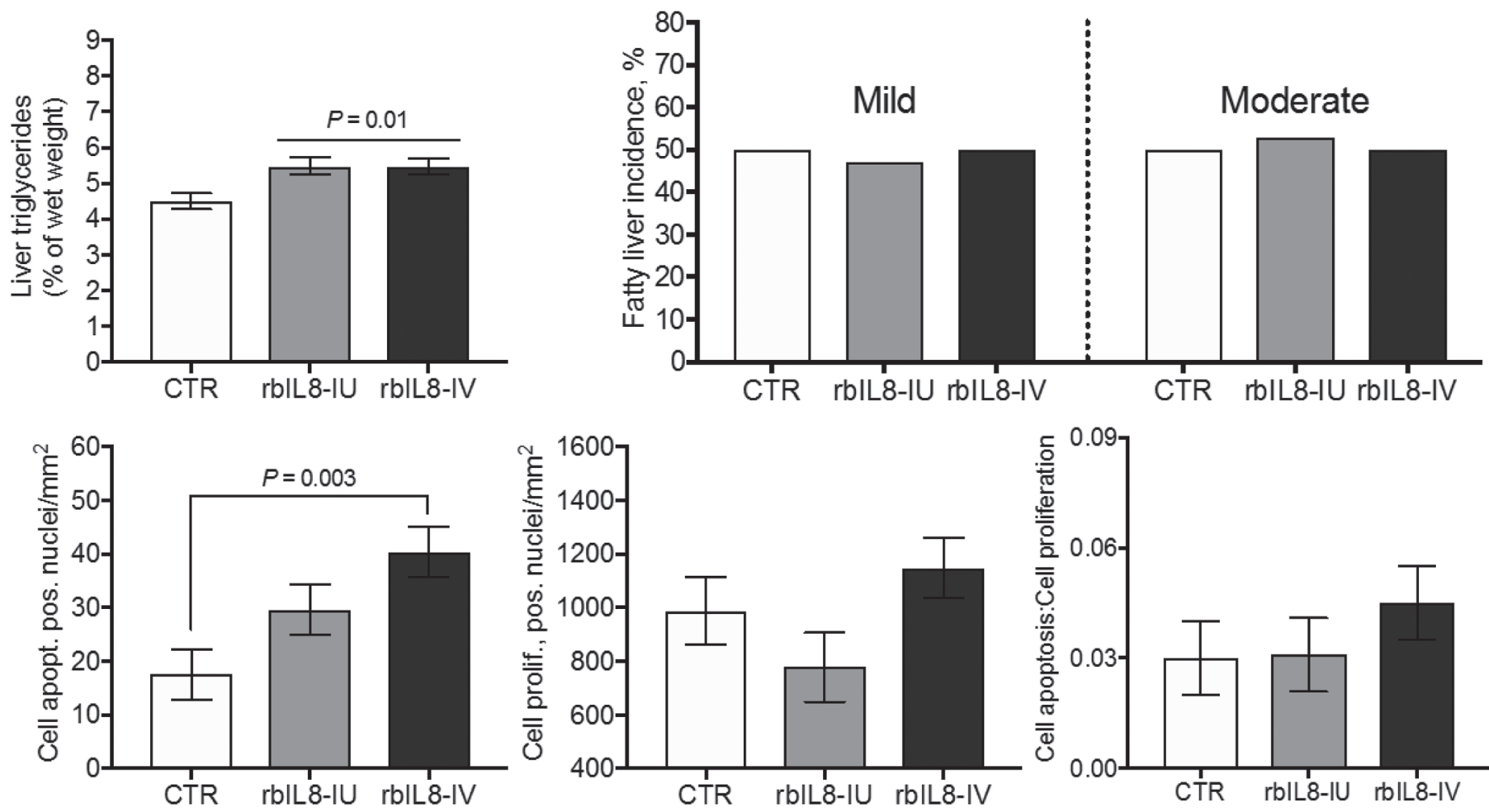

Figure 7. Liver triglyceride levels, liver cell proliferation (prolif.), and apoptosis (apopt.), the ratio of liver cell apoptosis to cell proliferation, and fatty liver incidence (based on triglyceride level analysis) of cows treated with recombinant bovine interleukin-8 intrauterine (rbIL8$\mathrm{IU}, \mathrm{n}=20$ ), intravenously ( $\mathrm{rbIL} 8-\mathrm{IV}, \mathrm{n}=20$ ), and controls $(\mathrm{CTR}, \mathrm{n}=20$ ). Liver biopsies were obtained $14 \mathrm{~d}$ after treatment. Fatty liver was categorized based on the percentage of liver triglycerides [normal liver ( $<1 \%$ of liver triglycerides), mild (1-5\% of liver triglycerides), moderate (5-10\% of liver triglycerides), and severe fatty liver ( $>10 \%$ of liver triglycerides); no cows were found with normal or severe fatty liver]. Results are presented as LSM \pm SEM for continuous data and as percentage incidence for categorical data. pos. $=$ positive. 
tion of feed intake. On the contrary, a study showed that intracerebroventricular administration of recombinant human IL-8 in rats was associated with reduced food intake (Plata-Salaman and Borkoski, 1993). In that study, however, the peripheral administration of recombinant human IL-8 in doses similar to those administered centrally did not alter food intake. Herein, the administration of rbIL8-IV was not associated with DMI. Moreover, rbIL-8 treatment administered intravenously or intrauterine did not alter plasma IL-8 levels. Thus, we suggest that IL- 8 does not increase DMI by stimulating the feeding centers of the brain. Uterine infections are associated with depressed DMI during the pre- and postpartum period (Hammon et al., 2006; Huzzey et al., 2007). Uterine diseases are highly associated with the presence of Escherichia coli and its LPS in lochia during the very early postpartum (Dohmen et al., 2000; Bicalho et al., 2012). We have demonstrated that rbIL- 8 is effective to attract neutrophils to the reproductive tract in Holstein animals (Bicalho et al., 2018). Moreover, rbIL8-IU treatment significantly reduced the incidence of puerperal metritis in multiparous cows (Zinicola et al., 2019a). The immune system energy expenditure is extremely high in dairy cows facing endotoxin challenges such as uterine bacterial infections (Kvidera et al., 2017). Thus, it is reasonable to surmise that an improved local immune response in the uterus caused by rbIL8-IU might have reduced the endotoxin challenges for these cows and triggered the increased DMI that drove the differences in milk production reported in the current study. However, more studies are needed to elucidate the mechanism by which rbIL8-IU treatment increases DMI in lactating cows.

An increase in hematocrit levels is characteristic of dehydration. Herein, we observed that rbIL8-IU cows tended to have lower hematocrit levels when compared with CTR cows. We also observed that cows treated with rbIL8-IU had significantly lower red blood cell numbers than CTR cows. In a dehydration status, the volume of fluid in the blood drops, thus the count of

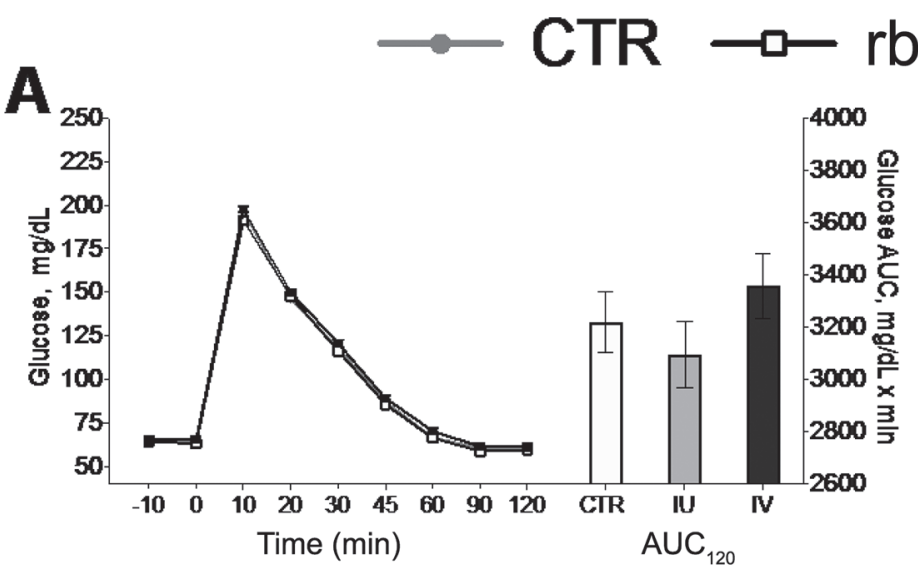

bIL8-IU rbIL8-IV

B 80
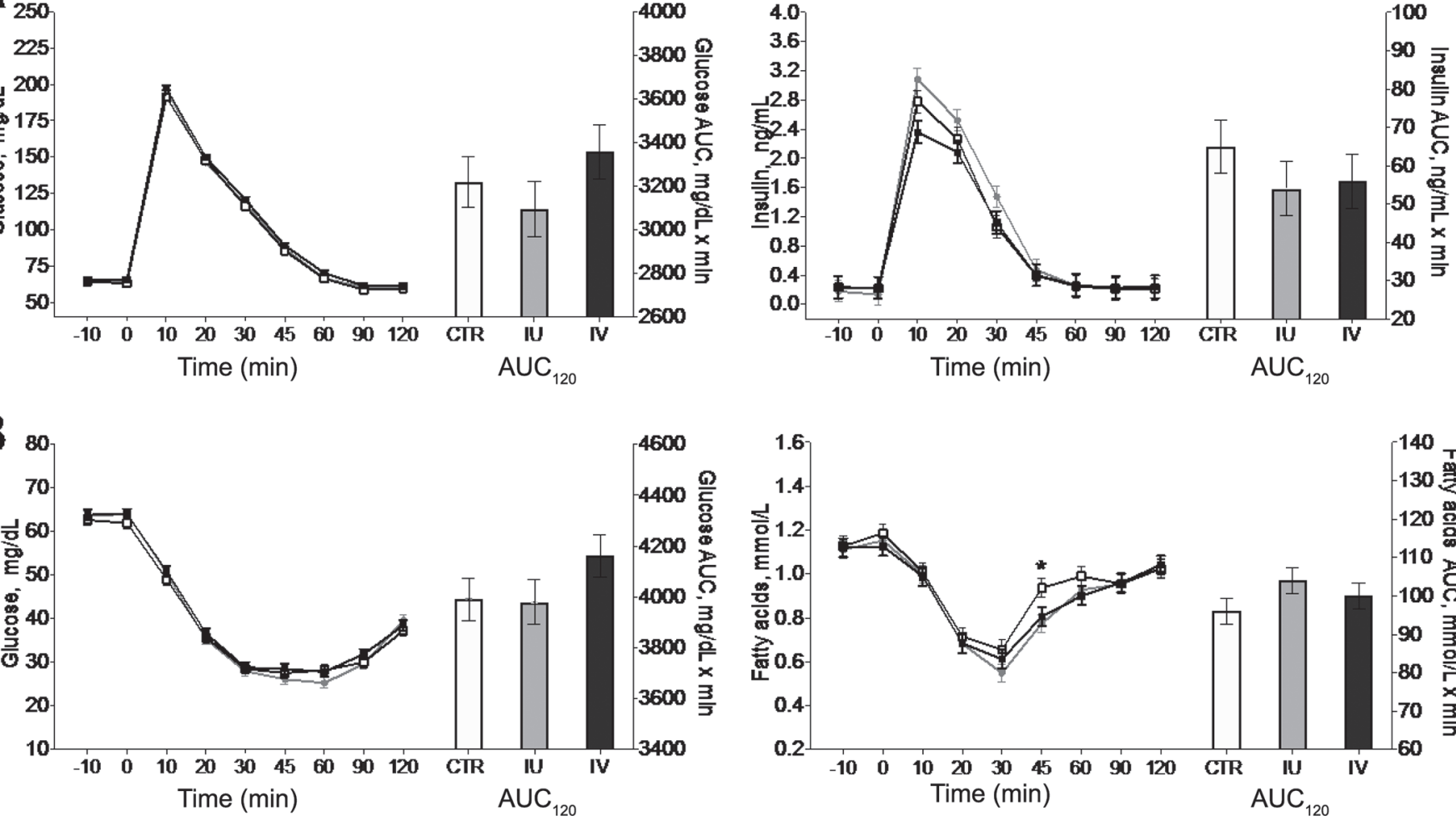

Figure 8. Glucose and insulin responses to intravenous glucose tolerance test (A) and intravenous insulin challenge test (B) of cows treated with recombinant bovine interleukin-8 intrauterine (rbIL8-IU, $\mathrm{n}=20)$, intravenously $(\mathrm{rbIL} 8-\mathrm{IV}, \mathrm{n}=20)$, and controls $(\mathrm{CTR}, \mathrm{n}=20)$. Intravenous glucose tolerance test and intravenous insulin challenge test were performed on DIM 10 and 11 , respectively. White bars, light gray bars, and dark gray bars represent the area under the curve [AUC; mg/dL (glucose), ng/mL (insulin), and mmol/L (fatty acids) per 120 min] of CTR, rbIL8-IU, and rbIL8-IV cows, respectively. ${ }^{*} P \leq 0.05$. Results are presented at LSM \pm SEM. 
red blood cells rises. Therefore, it is possible that water intake may have also increased in the rbIL8-IU-treated cows.

Long-term milk production responses were not observed in cows treated with rbIL8-IV. Cows treated with rbIL8-IV had similar DMI when compared with CTR cows. Therefore, considering that rbIL8-IU cows produced more milk and had significantly higher DMI than CTR cows, the lack of effect of rbIL8-IV treatment on milk production is not surprising. These results also provide further support to the notion that the observed increase in milk production and DMI as well as improved health following rbIL8-IU are a consequence of a local effect in the uterus.
One of the main hypotheses by which rbIL- 8 treatment increases milk production was through stimulation of insulin resistance. A study in the human literature demonstrated that IL-8 promotes insulin resistance via the inhibition of AKT activation through ERK or p38 MAPK pathways, or both (Kobashi et al., 2009). Moreover, we have demonstrated that repeated systemic administration of rbIL-8 in male Holstein calves induced a long-lasting state of insulin resistance (Zinicola et al., 2019b). In contrast with our hypothesis, in the present study rbIL-8 treatment did not affect peripheral tissue insulin sensitivity, as measured by IVGTT, IVICT, and insulin sensitivity indexes. Thus, we can conclude that promoting insulin resistance does not seems to be the
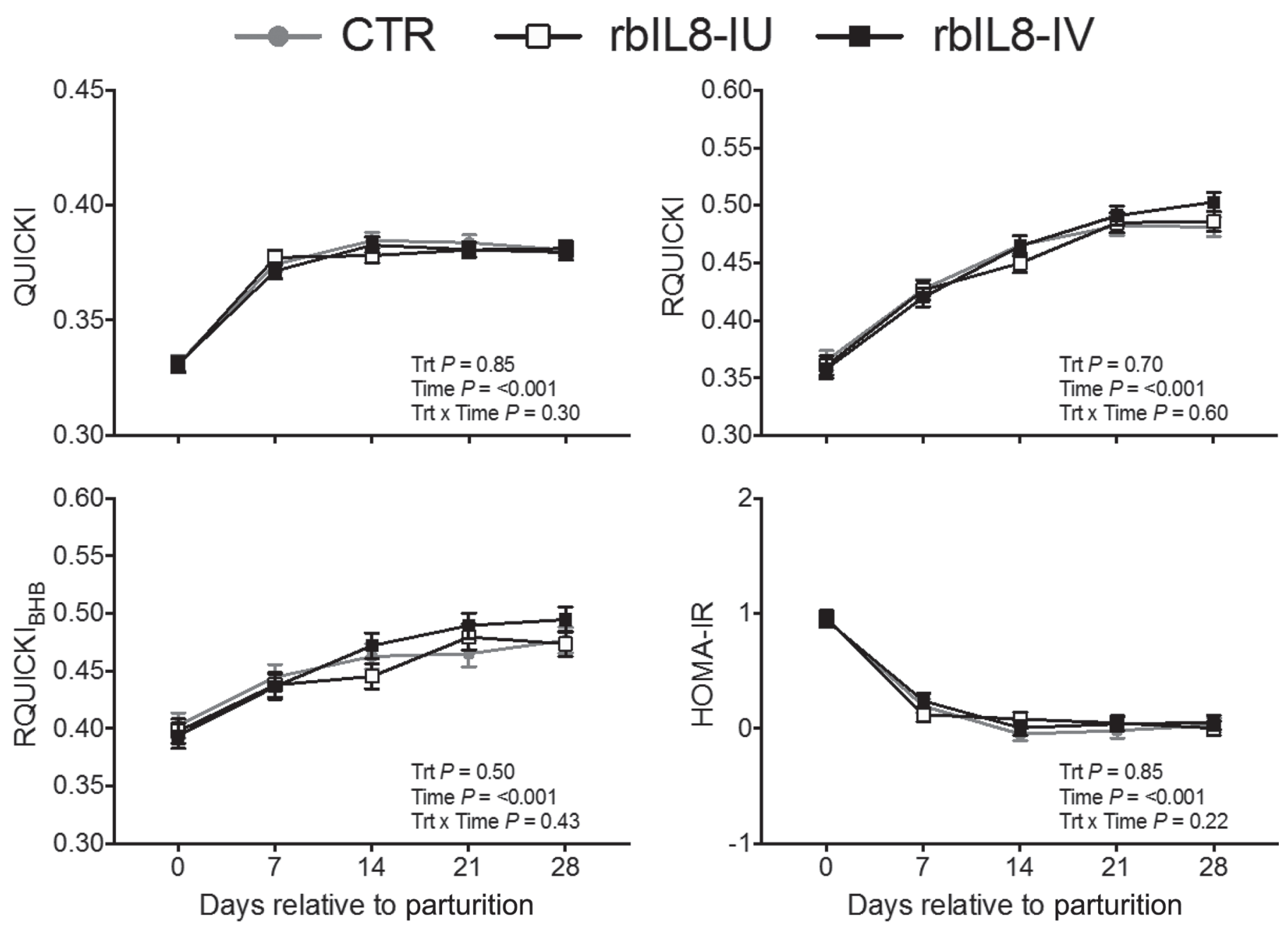

Figure 9. Insulin sensitivity indexes for the first 4 wk of lactation of cows treated with recombinant bovine interleukin-8 intrauterine (rbIL8$\mathrm{IU}, \mathrm{n}=70$ ), intravenously (rbIL8-IV, $\mathrm{n}=70)$, and controls $(\mathrm{CTR}, \mathrm{n}=70)$. Quantitative insulin sensitivity check index $(\mathrm{QUICKI})=\{1 /[\log$ insulin $(\mu \mathrm{U} / \mathrm{mL})+\log$ glucose $(\mathrm{mg} / \mathrm{dL})]\}$; revised QUICKI (RQUICKI) $=\{1 /[\log$ glucose $(\mathrm{mg} / \mathrm{dL})+\log$ insulin $(\mu \mathrm{U} / \mathrm{mL})+\log$ fatty acids $(\mathrm{mmol} / \mathrm{L})]\}$; revised QUICKI including BHB $\left(\mathrm{RQUICKI}_{\mathrm{BHB}}\right)=\{1 /[\log$ glucose $(\mathrm{mg} / \mathrm{dL})+\log$ insulin $(\mu \mathrm{U} / \mathrm{mL})+\log$ fatty acids $(\mathrm{mmol} / \mathrm{L})+$ $\log \mathrm{BHB}(\mathrm{mmol} / \mathrm{L})]\}$; and the homeostatic model assessment of insulin resistance $(\mathrm{HOMA}-\mathrm{IR})=\{[\mathrm{glucose}(\mathrm{mmol} / \mathrm{L}) \times \mathrm{insulin}(\mu \mathrm{U} / \mathrm{mL})] / 22.5\}$. Results are presented as LSM \pm SEM. Trt = treatment. 


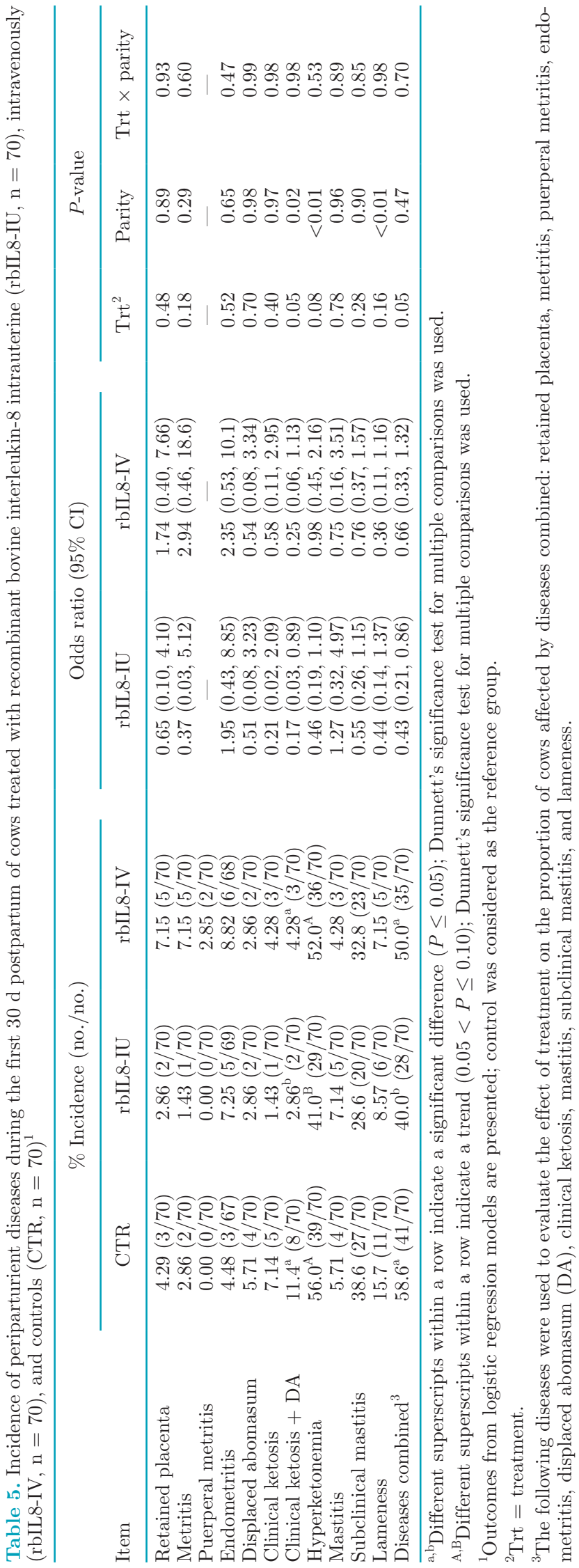

mechanism by which rbIL8-IU treatment increases milk yield in cows.

We also observed that rbIL8-IU treatment reduced the incidence of postpartum HYK, which also agrees with our previous findings (Zinicola et al., 2019a). We have proposed that the underlying mechanism by which rbIL8-IU reduces the incidence of HYK could be increased liver cell proliferation, reduced apoptosis, or both (Colletti et al., 1998; Osawa et al., 2002). The increased number of cells available to oxidize fatty acids could lower BHB production and lower TG accumulation within hepatocytes (Zinicola et al., 2019a). However, in the current study rbIL8-IU treatment did not alter cell turnover indices, as the ratio of liver cell apoptosis to cell proliferation (indicative of cell production) was similar among treatments. Thus, the observed increased DMI in cows treated with rbIL8-IU leads us to suggest that lower incidence of HYK following rbIL8-IU administration may be as a consequence of higher DMI. Along this line, we also suggest that the observed reduced incidence of diseases in cows treated with rbIL8-IU might be a result of increased DMI. However, it is unclear if the increased DMI resulted in improved health or if the improved health resulted in higher DMI.

It is surprising that cows treated with rbIL8-IU and rbIL8-IV had higher levels of liver TG when no effects on rbIL-8 treatment on peripheral tissue insulin sensitivity, plasma concentrations of fatty acids, $\mathrm{BHB}$, and liver cell production were found. We do not have a clear explanation for this observation. In lactating cows, the accumulation of TG in the liver begin near to the central hepatic vein and progresses toward the midzonal region of the liver (Veenhuizen et al., 1991). Since the collection of liver tissue sample is a blind procedure, it is possible that liver samples could have been taken from different areas of the liver, and thus affecting the interpretation of the results. Therefore, the increased liver TG concentration observed as a consequence of rbIL-8 treatment could have been a type I error. Further investigations are needed to confirm whether increased liver TG levels should be expected in cows treated with rbIL-8. Besides the observed significant increase of liver TG levels in treated cows, it is important to highlight that when cows were categorized into normal, mild, moderate, and severe fatty liver based on TG concentration (Bobe et al., 2004), no differences were observed between treatment groups. The incidence of fatty liver is associated with the incidence of ketosis (Veenhuizen et al., 1991). In the present study, despite the observed increase on liver TG levels in cows treated with rbIL-8, the incidence of CK was not affected by treatment. Indeed, a numerical reduction of $\mathrm{CK}$ incidence was observed in cows treated with rbIL-8. Additionally, no 
differences were detected on hepatic enzymes and other indirect markers of liver functionality/damage between treatment groups.

Cytokines are known to alter the GH signaling via suppressors of cytokine signaling protein production (Rico-Bautista et al., 2006). In a previous study, we suggested that rbIL-8 treatment might favor the uncoupling of the GH/IGF-1 axis that postpartum cows experience during early lactation as a homeorhetic shift to support milk production (Zinicola et al., 2019a). In contrast with this hypothesis, we have shown that Holstein calves treated with rbIL- 8 have similar GH and IGF-1 concentrations than placebo-treated calves (Zinicola et al., 2019b). In the present study, plasma GH and IGF-1 levels were not affected by treatment. Therefore, it is reasonable to suggest that rbIL- 8 treatment does not alter the GH and IGF-1 axis in dairy cows.

Moreover, in a previous study we also hypothesized that the observed higher milk yield following rbIL-8 treatment might be a result of increased mammary cell number. The activation of NF- $\kappa \mathrm{B}$ during mammary gland development is critical for mammary cell differentiation (Brantley et al., 2001; Cao et al., 2001). Interleukin-8 is known as an activator of NF- $\kappa \mathrm{B}$ (Bendre et al., 2003), which will upregulate cycling D1 and therefore promote cell differentiation (Srivastava et al., 2003). Considering the observed increased DMI in cows treated with rbIL8-IU, we surmise that it is unlikely that IL-8 would increase milk production by increasing mammary gland cell proliferation. However, further studies are needed to assess this possibility.

In agreement with our previous study, plasma haptoglobin concentrations and RT were not affected by rbIL-8 treatment (Zinicola et al., 2019a). In addition, we did not observe changes in blood cell numbers between treatment groups. These results suggest that the administration of rbIL-8 in lactating cows does not alter systemic inflammation.

In a previous study we showed that a single intrauterine administration of rbIL- 8 within $12 \mathrm{~h}$ of parturition in multiparous cows was associated with a significant reduction of puerperal metritis (Zinicola et al., 2019a). In that study the incidence of puerperal metritis in multiparous placebo-treated cows was $34 \%$, and in the current study the incidence of puerperal metritis was $0 \%$. Moreover, the incidence of metritis observed in the present study was also very low $(3 \%)$ when compared with previous studies (Galvão et al., 2009; LeBlanc et al., 2011; Zinicola et al., 2018). Herein, we observed that cows treated with rbIL8-IU had lower incidence of $\mathrm{RP}$ and metritis, both only numerically. Thus, the lack of significant preventative effects following rbIL8-IU treatment on uterine diseases may be due to the very low number of observations and a low statistical power.

\section{CONCLUSIONS}

This study was conducted to explore underlying mechanisms by which rbIL- 8 treatment increases milk production in Holstein cows. We observed that cows treated with rbIL8-IU produced more milk, FCM, and ECM yields than CTR cows, with no changes on BCS, BW, and EBAL. In contrast to our hypotheses, no differences were observed in metabolism in response to rbIL-8 treatment. Moreover, rbIL8-IU treatment significantly increased DMI during the first 4 wk postpartum. The administration of rbIL8-IU also reduced the incidence of HYK and improved overall postpartum health. We conclude that the long-term effects of rbIL8-IU treatment on milk production and health may be mainly because of increased DMI. Further research is necessary to elucidate the mechanism by which IU administration of rbIL-8 increases voluntary feed intake in lactating cows. This study supports the use of rbIL-8 administered IU shortly after calving to improve health and production responses in lactating cows.

\section{ACKNOWLEDGMENTS}

This work was partially supported by Zoetis Animal Health (Kalamazoo, MI) and by Agriculture and Food Research Initiative Competitive Grant No. 201767015-26541 from the United States Department of Agriculture National Institute of Food and Agriculture (Washington, DC).

\section{REFERENCES}

Apostolakis, S., G. K. Chalikias, D. N. Tziakas, and S. Konstantinides. 2011. Erythrocyte Duffy antigen receptor for chemokines (DARC): Diagnostic and therapeutic implications in atherosclerotic cardiovascular disease. Acta Pharmacol. Sin. 32:417-424.

Balogh, O., O. Szepes, K. Kovacs, M. Kulcsar, J. Reiczigel, J. A. Alcazar, M. Keresztes, H. Febel, J. Bartyik, S. G. Fekete, L. Fesus, and G. Huszenicza. 2008. Interrelationships of growth hormone AluI polymorphism, insulin resistance, milk production and reproductive performance in Holstein-Friesian cows. Vet. Med. Czech. 53:604-616.

Bauman, D. E., and W. B. Currie. 1980. Partitioning of nutrients during pregnancy and lactation: A review of mechanisms involving homeostasis and homeorhesis. J. Dairy Sci. 63:1514-1529.

Bauman, D. E., and R. G. Vernon. 1993. Effects of exogenous bovine somatotropin on lactation. Annu. Rev. Nutr. 13:437-461.

Baumgard, L. H., R. J. Collier, and D. E. Bauman. 2017. A 100-Year Review: Regulation of nutrient partitioning to support lactation. J. Dairy Sci. 100:10353-10366.

Bazan, J. F. 1989. A novel family of growth factor receptors: A common binding domain in the growth hormone, prolactin, erythropoietin and IL-6 receptors, and the p75 IL-2 receptor beta-chain. Biochem. Biophys. Res. Commun. 164:788-795. 
Bell, A. W. 1995. Regulation of organic nutrient metabolism during transition from late pregnancy to early lactation. J. Anim. Sci. $73: 2804-2819$

Bell, A. W., and D. E. Bauman. 1997. Adaptations of glucose metabolism during pregnancy and lactation. J. Mammary Gland Biol. Neoplasia 2:265-278.

Bendre, M. S., D. C. Montague, T. Peery, N. S. Akel, D. Gaddy, and L. J. Suva. 2003. Interleukin-8 stimulation of osteoclastogenesis and bone resorption is a mechanism for the increased osteolysis of metastatic bone disease. Bone 33:28-37.

Bernard, J. K. 1997. Milk production and composition responses to the source of protein supplements in diets containing wheat middlings. J. Dairy Sci. 80:938-942.

Bicalho, L. M. S., M. Zinicola, V. S. Machado, F. S. Lima, A. G. V. Teixeira, C. Narbus, M. R. Xavier, H. Higgins, and R. C. Bicalho. 2019. Effects of recombinant bovine interleukin-8 (rbIL-8) treatment on health, metabolism, and lactation performance in Holstein cattle I: Production and functional characterization of rbIL-8 in vitro and in vivo. J. Dairy Sci. 102:10304-10315. https://doi .org/10.3168/jds.2019-16334.

Bicalho, M. L., E. C. Marques, R. O. Gilbert, and R. C. Bicalho. 2017. The association of plasma glucose, BHBA, and NEFA with postpartum uterine diseases, fertility, and milk production of Holstein dairy cows. Theriogenology 88:270-282.

Bicalho, M. L. S., V. S. Machado, G. Oikonomou, R. O. Gilbert, and R. C. Bicalho. 2012. Association between virulence factors of Escherichia coli, Fusobacterium necrophorum, and Arcanobacterium pyogenes and uterine diseases of dairy cows. Vet. Microbiol. 157:125-131.

Bobe, G., J. W. Young, and D. C. Beitz. 2004. Invited review: Pathology, etiology, prevention, and treatment of fatty liver in dairy cows. J. Dairy Sci. 87:3105-3124.

Brantley, D. M., C. L. Chen, R. S. Muraoka, P. B. Bushdid, J. L. Bradberry, F. Kittrell, D. Medina, L. M. Matrisian, L. D. Kerr, and F. E. Yull. 2001. Nuclear factor-kappaB (NF-kappaB) regulates proliferation and branching in mouse mammary epithelium. Mol. Biol. Cell 12:1445-1455.

Butler, S. T., A. L. Marr, S. H. Pelton, R. P. Radcliff, M. C. Lucy, and W. R. Butler. 2003. Insulin restores GH responsiveness during lactation-induced negative energy balance in dairy cattle: Effects on expression of IGF-I and GH receptor 1A. J. Endocrinol. 176:205-217.

Butler, S. T., S. H. Pelton, and W. R. Butler. 2004. Insulin increases 17 beta-estradiol production by the dominant follicle of the first postpartum follicle wave in dairy cows. Reproduction 127:537-545.

Cao, Y., G. Bonizzi, T. N. Seagroves, F. R. Greten, R. Johnson, E. V. Schmidt, and M. Karin. 2001. IKKalpha provides an essential link between RANK signaling and cyclin D1 expression during mammary gland development. Cell 107:763-775.

Cardoso, F. C., W. Sears, S. J. LeBlanc, and J. K. Drackley. 2011 Technical note: Comparison of 3 methods for analyzing areas under the curve for glucose and nonesterified fatty acids concentrations following epinephrine challenge in dairy cows. J. Dairy Sci. 94:6111-6115.

Chapinal, N., M. E. Carson, S. J. LeBlanc, K. E. Leslie, S. Godden, M. Capel, J. E. Santos, M. W. Overton, and T. F. Duffield. 2012. The association of serum metabolites in the transition period with milk production and early-lactation reproductive performance. J. Dairy Sci. 95:1301-1309.

Colletti, L. M., M. Green, M. D. Burdick, S. L. Kunkel, and R. M. Strieter. 1998. Proliferative effects of CXC chemokines in rat hepatocytes in vitro and in vivo. Shock 10:248-257.

De Koster, J. D., and G. Opsomer. 2013. Insulin resistance in dairy cows. Vet. Clin. North Am. Food Anim. Pract. 29:299-322.

Dillingh, M. R., E. P. van Poelgeest, K. E. Malone, E. M. Kemper, E. S. G. Stroes, M. Moerland, and J. Burggraaf. 2014. Characterization of inflammation and immune cell modulation induced by low-dose LPS administration to healthy volunteers. J. Inflamm. (Lond.) 11:28.

Dohmen, M. J., K. Joop, A. Sturk, P. E. Bols, and J. A. Lohuis. 2000. Relationship between intra-uterine bacterial contamination, endo- toxin levels and the development of endometritis in postpartum cows with dystocia or retained placenta. Theriogenology 54:10191032

Dubuc, J., T. F. Duffield, K. E. Leslie, J. S. Walton, and S. J. Leblanc. 2011. Effects of postpartum uterine diseases on milk production and culling in dairy cows. J. Dairy Sci. 94:1339-1346.

Edmonson, A. J., I. J. Lean, L. D. Weaver, T. Farver, and G. Webster. 1989. A body condition scoring chart for Holstein dairy cows. J. Dairy Sci. 72:68-78.

Fletcher, M. J. 1968. A colorimetric method for estimating serum triglycerides. Clin. Chim. Acta 22:393-397.

Folch, J., M. Lees, and G. H. Sloane Stanley. 1957. A simple method for the isolation and purification of total lipids from animal tissues. J. Biol. Chem. 226:497-509.

Foster, L. B., and R. T. Dunn. 1973. Stable reagents for determination of serum triglycerides by a colorimetric Hantzsch condensation method. Clin. Chem. 19:338-340

Fujishiro, M., Y. Gotoh, H. Katagiri, H. Sakoda, T. Ogihara, M. Anai, Y. Onishi, H. Ono, M. Abe, N. Shojima, Y. Fukushima, M. Kikuchi, Y. Oka, and T. Asano. 2003. Three mitogen-activated protein kinases inhibit insulin signaling by different mechanisms in 3T3L1 adipocytes. Mol. Endocrinol. 17:487-497.

Hammon, D. S., I. M. Evjen, T. R. Dhiman, J. P. Goff, and J. L. Walters. 2006. Neutrophil function and energy status in Holstein cows with uterine health disorders. Vet. Immunol. Immunopathol. 113:21-29

Hardy, O. T., R. A. Perugini, S. M. Nicoloro, K. Gallagher-Dorval, V. Puri, J. Straubhaar, and M. P. Czech. 2011. Body mass indexindependent inflammation in omental adipose tissue associated with insulin resistance in morbid obesity. Surg. Obes. Relat. Dis. $7: 60-67$.

Hogaboam, C. M., C. L. Bone-Larson, M. L. Steinhauser, N. W. Lukacs, L. M. Colletti, K. J. Simpson, R. M. Strieter, and S. L. Kunkel. 1999. Novel CXCR2-dependent liver regenerative qualities of ELR-containing CXC chemokines. FASEB J. 13:1565-1574.

Holmes, W. E., J. Lee, W. J. Kuang, G. C. Rice, and W. I. Wood 1991. Structure and functional expression of a human interleukin- 8 receptor. Science 253:1278-1280.

Holtenius, P., and K. Holtenius. 2007. A model to estimate insulin sensitivity in dairy cows. Acta Vet. Scand. 49:29.

Huzzey, J. M., D. M. Veira, D. M. Weary, and M. A. von Keyserlingk. 2007. Prepartum behavior and dry matter intake identify dairy cows at risk for metritis. J. Dairy Sci. 90:3220-3233.

Katz, A., S. S. Nambi, K. Mather, A. D. Baron, D. A. Follmann, G. Sullivan, and M. J. Quon. 2000. Quantitative insulin sensitivity check index: A simple, accurate method for assessing insulin sensitivity in humans. J. Clin. Endocrinol. Metab. 85:2402-2410.

Kelton, D. F., K. D. Lissemore, and R. E. Martin. 1998. Recommendations for recording and calculating the incidence of selected clinical diseases of dairy cattle. J. Dairy Sci. 81:2502-2509.

Kobashi, C., S. Asamizu, M. Ishiki, M. Iwata, I. Usui, K. Yamazaki K. Tobe, M. Kobayashi, and M. Urakaze. 2009. Inhibitory effect of IL-8 on insulin action in human adipocytes via MAP kinase pathway. J. Inflamm. (Lond.) 6:25.

Kvidera, S. K., E. A. Horst, M. Abuajamieh, E. J. Mayorga, M. V. Fernandez, and L. H. Baumgard. 2017. Glucose requirements of an activated immune system in lactating Holstein cows. J. Dairy Sci. 100:2360-2374.

Langhans, W., and B. Hrupka. 1999. Interleukins and tumor necrosis factor as inhibitors of food intake. Neuropeptides 33:415-424.

LeBlanc, S. J., T. Osawa, and J. Dubuc. 2011. Reproductive tract defense and disease in postpartum dairy cows. Theriogenology $76: 1610-1618$

Lucy, M. C., G. A. Verkerk, B. E. Whyte, K. A. Macdonald, L. Burton, R. T. Cursons, J. R. Roche, and C. W. Holmes. 2009. Somatotropic axis components and nutrient partitioning in genetically diverse dairy cows managed under different feed allowances in a pasture system. J. Dairy Sci. 92:526-539.

Martich, G. D., R. L. Danner, M. Ceska, and A. F. Suffredini. 1991 Detection of interleukin-8 and tumor necrosis factor in normal hu- 
mans after intravenous endotoxin: The effect of anti-inflammatory agents. J. Exp. Med. 173:1021-1024.

Mulligan, K. X., R. T. Morris, Y. F. Otero, D. H. Wasserman, and O. P. McGuinness. 2012. Disassociation of muscle insulin signaling and insulin-stimulated glucose uptake during endotoxemia. PLoS One 7:e30160.

Muniyappa, R., S. Lee, H. Chen, and M. J. Quon. 2008. Current approaches for assessing insulin sensitivity and resistance in vivo: Advantages, limitations, and appropriate usage. Am. J. Physiol. Endocrinol. Metab. 294:E15-E26.

Nordlund, K. 1987. Adjusted corrected milk. Bovine Proc. 19:87-89.

NRC. 2001. Nutrient Requirements of Dairy Cattle. 7th rev. ed. National Academy Press, Washington, DC.

Onuffer, J. J., and R. Horuk. 2002. Chemokines, chemokine receptors and small-molecule antagonists: Recent developments. Trends Pharmacol. Sci. 23:459-467.

Osawa, Y., M. Nagaki, Y. Banno, D. A. Brenner, T. Asano, Y. Nozawa, H. Moriwaki, and S. Nakashima. 2002. Tumor necrosis factor alpha-induced interleukin-8 production via NF-B and phosphatidylinositol 3-kinase/Akt pathways inhibits cell apoptosis in human hepatocytes. Infect. Immun. 70:6294-6301.

Perseghin, G., A. Caumo, M. Caloni, G. Testolin, and L. Luzi. 2001. Incorporation of the fasting plasma FFA concentration into QUICKI improves its association with insulin sensitivity in nonobese individuals. J. Clin. Endocrinol. Metab. 86:4776-4781.

Plata-Salaman, C. R., and J. P. Borkoski. 1993. Interleukin-8 modulates feeding by direct action in the central nervous system. Am. J. Physiol. 265:R877-R882.

Plaut, K., D. E. Bauman, N. Agergaard, and R. M. Akers. 1987. Effect of exogenous prolactin administration on lactational performance of dairy cows. Domest. Anim. Endocrinol. 4:279-290.

Plum, L., M. Schubert, and J. C. Bruning. 2005. The role of insulin receptor signaling in the brain. Trends Endocrinol. Metab. 16:59-65.

Rico-Bautista, E., A. Flores-Morales, and L. Fernandez-Perez. 2006. Suppressor of cytokine signaling (SOCS) 2, a protein with multiple functions. Cytokine Growth Factor Rev. 17:431-439.

Romanatto, T., M. Cesquini, M. E. Amaral, E. A. Roman, J. C. Moraes, M. A. Torsoni, A. P. Cruz-Neto, and L. A. Velloso. 2007. TNF-alpha acts in the hypothalamus inhibiting food intake and increasing the respiratory quotient-effects on leptin and insulin signaling pathways. Peptides 28:1050-1058.

Rosemberg, E., M. L. Thonney, and W. R. Butler. 1989. The effects of bovine growth hormone and thyroxine on growth rate and carcass measurements in lambs. J. Anim. Sci. 67:3300-3312.

Schutz, M. M. 1994. Genetic evaluation of somatic cell scores for United States dairy cattle. J. Dairy Sci. 77:2113-2129.

Sheldon, I. M., G. S. Lewis, S. LeBlanc, and R. O. Gilbert. 2006. Defining postpartum uterine disease in cattle. Theriogenology 65:1516-1530.
Spurlock, M. E. 1997. Regulation of metabolism and growth during immune challenge: An overview of cytokine function. J. Anim. Sci. $75: 1773-1783$

Srivastava, S., M. Matsuda, Z. Hou, J. P. Bailey, R. Kitazawa, M. P. Herbst, and N. D. Horseman. 2003. Receptor activator of NF-kappaB ligand induction via Jak2 and Stat5a in mammary epithelial cells. J. Biol. Chem. 278:46171-46178.

Stevenson, N. J., S. Haan, A. E. McClurg, M. J. McGrattan, M. A. Armstrong, P. C. Heinrich, and J. A. Johnston. 2004. The chemoattractants, IL-8 and formyl-methionyl-leucyl-phenylalanine, regulate granulocyte colony-stimulating factor signaling by inducing suppressor of cytokine signaling-1 expression. J. Immunol. $173: 3243-3249$

Veenhuizen, J. J., J. K. Drackley, M. J. Richard, T. P. Sanderson, L. D. Miller, and J. W. Young. 1991. Metabolic changes in blood and liver during development and early treatment of experimental fatty liver and ketosis in cows. J. Dairy Sci. 74:4238-4253.

Wijma, R., M. M. Perez, M. Masello, M. L. Stangaferro, and J. O. Giordano. 2018. A resynchronization of ovulation program based on ovarian structures present at nonpregnancy diagnosis reduced time to pregnancy in lactating dairy cows. J. Dairy Sci. 101:16971707.

Yuan, K., J. K. Farney, L. K. Mamedova, L. M. Sordillo, and B. J. Bradford. 2013. TNFalpha altered inflammatory responses, impaired health and productivity, but did not affect glucose or lipid metabolism in early-lactation dairy cows. PLoS One 8:e80316.

Zinicola, M., and R. C. Bicalho. 2019. Association of peripartum plasma insulin concentration with milk production, colostrum insulin levels, and plasma metabolites of Holstein cows. J. Dairy Sci. 102:1473-1482.

Zinicola, M., M. L. S. Bicalho, T. Santin, E. C. Marques, R. S. Bisinotto, and R. C. Bicalho. 2019a. Effects of recombinant bovine interleukin-8 (rbIL-8) treatment on health, metabolism, and lactation performance in Holstein cattle II: Postpartum uterine health, ketosis, and milk production. J. Dairy Sci. 102:10316-10328. https: //doi.org/10.3168/jds.2019-16335.

Zinicola, M., P. R. Menta, B. L. Ribeiro, Y. Boisclair, and R. C. Bicalho. 2019b. Effects of recombinant bovine interleukin-8 (rbIL-8) treatment on health, metabolism, and lactation performance in Holstein cattle III: Administration of rbIL-8 induces insulin resistance in bull calves. J. Dairy Sci. 102:10329-10339. https://doi .org/10.3168/jds.2019-16336.

Zinicola, M., H. Korzec, A. G. V. Teixeira, E. K. Ganda, L. Bringhenti, A. C. C. H. Tomazi, R. O. Gilbert, and R. C. Bicalho. 2018 Effects of pegbovigrastim administration on periparturient diseases, milk production, and reproductive performance of Holstein cows. J. Dairy Sci. 101:11199-11217. https://doi.org/10.3168/jds 2018-14869. 